\title{
Glycoconjugate probes and targets for molecular imaging using magnetic resonance
}

Recently, many research activities in medical diagnosis have been devoted to molecular imaging with MRI. A key issue is the evaluation of molecular targets that allow the early detection and characterization of diseases and the assessment of the effects of therapy. The majority of the current targeting vectors are peptides and proteins; reports on carbohydrate-based probes are relatively scarce. However, molecular recognitions involving carbohydrates are ubiquitous in both normal and pathological natural processes. Here, we critically review the literature on the development and validation of MRI probes using carbohydrates either as targets or targeting vectors. Exploitation of molecular recognition involving carbohydrates in MRI looks promising. Amplification techniques may be important for overcoming sensitivity problems.

\section{Molecular recognition of sugar} residues applied in molecular imaging Molecular imaging aims at probing the molecular abnormalities that are the basis of diseases rather than to image their effects [1]. An important prerequisite of this approach is the selection of appropriate markers of disease and of targeting vectors to recognize them. The latter can include low-molecular weight substrates for enzymes or high-molecular weight affinity ligands, such as monoclonal antibodies, hormone analogs and recombinant proteins. Of the three major classes of biomolecules (proteins, nucleic acids and carbohydrates), the latter class is the least exploited in molecular imaging. However, a dense layer of glycoconjugates covers all cells and carbohydrate mediated cellular recognition plays an important role in nature, both in normal and malignant processes, such as cell-cell communication, infection, inflammation, metastasis and reproduction. As carriers of information, the carbohydrates have far greater potential than proteins and nucleic acids; three different nucleotides or amino acids can generate only six distinguishable structures, while over 1000 structures can be built up from three different monosaccharides [2]. This level of complexity is probably the reason for the fact that the exploration of these compounds in molecular imaging is lagging behind [3]. Recently, significant progress has been made in glycochemistry and glycobiology; for example, automated solid-phase synthesis of oligosaccharides has become possible [4], carbohydrate-based vaccines have been developed [5] and high-throughput methods have been designed for the screening of molecular interactions [6]. The exciting new developments in glycoscience are opening way for new challenges in exploring the full potential of carbohydrates in molecular imaging. Therefore, here we give an overview of the recent literature on the use of glycoconjugates either as probes or targets in molecular imaging using MRI.

MRI contrast agents (CAs) are broadly described as positive or negative, depending on whether they give rise to a brightening or a darkening effect on the MR image, respectively. The positive or brightening effect predominantly relates to the longitudinal proton relaxation time $\left(\mathrm{T}_{1}\right)$ and the negative or darkening effect predominantly relates to the transverse proton relaxation time $\left(\mathrm{T}_{2}\right)$. To date, the majority of commercially available and clinically applied positive CAs are $\mathrm{Gd}^{3+}$ complexes of the polyaminocarboxylates diethylene triamine pentacetic acid (DTPA) and 1,4,7,10-tetraazacyclododecane-1,4,7,10tetraacetic acid (DOTA) (see Figure I for some typical examples) and negative CAs are various iron oxide particles. These agents are not actively targeting. The targeted CAs for application in molecular imaging that are currently under development and described below are generally based on compounds I (Gd-DTPA) and 2 (Gd-DOTA), as well as iron oxide nanoparticles.

\section{Carlos FGC Geraldes't, Kristina Djanashvilii ${ }^{2 \dagger}$ \& Joop A Peters ${ }^{2}$ \\ ${ }^{\dagger}$ Authors for correspondence \\ 'Departamento de Bioquímica, \\ Faculdade de Ciências e \\ Tecnologica, e Centro \\ de Neurociências e \\ Biologia Celular, \\ Universidade de Coimbra, \\ 3049 Coimbra, Portugal \\ Tel.: +35 I239853608 \\ E-mail: geraldes@bioq.uc.pt \\ ${ }^{2}$ Biocatalysis and Organic \\ Chemistry, Department of \\ Biotechnology, Delft University \\ of Technology, Julianalaan I36, \\ 2628 BL Delft, The Netherlands \\ Tel.: +3I I52 785092 \\ E-mail: k.djanashvili@tudelft.nl}

Molecular IMAGING

The in vivo characterization and measurement of biological

processes at the cellular and molecular level 


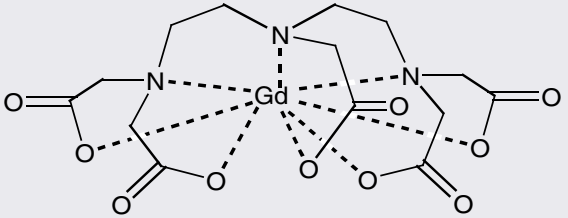

(1) Gd-DTPA (Magnevist)

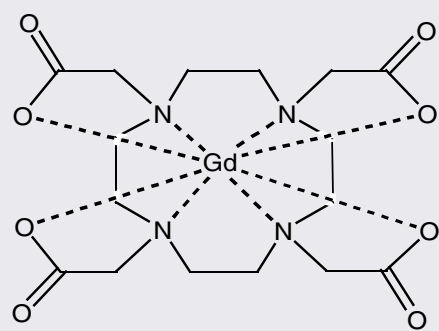

(2) Gd-DOTA (Dotarem)

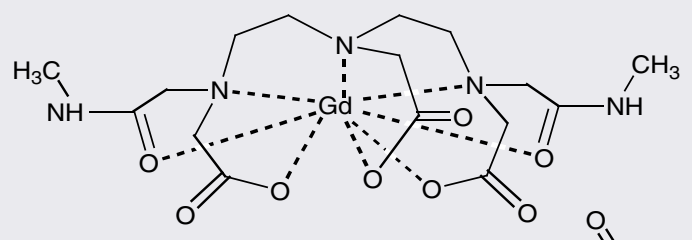

(3) Gd-DTPA-BMA (Omniscan)

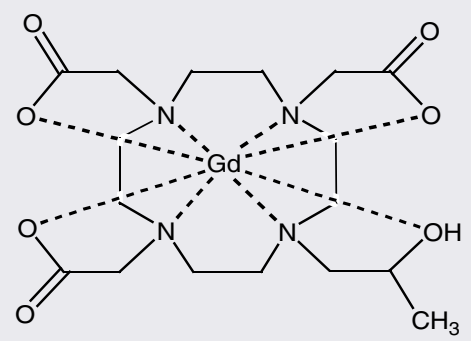

(4) Gd-HPDO3A (Prohance)

Figure 1. Typical examples of current clinically applied Gd-based MRI contrast agents. Charges and Gd-coordinated water molecules are omitted for clarity.

\section{Glycoconjugates}

Carbohydrates covalently linked with other biologically important chemical species, such as proteins and lipids. They are involved in cell-cell interactions

Molecular RECOGNITION

The specific interaction between two or more molecules through noncovalent bonding, which plays a major role in biological processes

MRI CONTRAST AGENTS

Paramagnetic materials that decrease the NMR relaxation times of water protons, resulting in the increase of the contrast in MRI images. These materials include Gd(III)complexes and iron oxide particles

\section{Ln-chelate glycoconjugates as molecular imaging CAs}

- Ln-chelate glycoconjugates as CAs for liver imaging using lectins as targets

Lectins are carbohydrate-binding proteins that specifically bind to the oligosaccharide moieties of glycoproteins and glycolipids. They also have the capability of recognizing a large variety of natural and artificial polysaccharidelike molecules with various different structures, such as heparin sulphate and hyaluronic acid proteoglycans [7-9]. A cluster glycoside effect, which describes the affinity enhancement (typically of orders of magnitude) involved in multivalent binding of several carbohydrate residues [10], has been found to operate in these lectin-carbohydrate interactions. Individual CRDs interact specifically with sugars (e.g., glucose, mannose and galactose) with affinity constants (lectin-monomeric sugar) in the millimolar range. However, assembly of monomeric units in oligomeric lectins results in the display of an array of CRDs with a variety of topologies, which, together with the topology (relative orientation and spacing) of the glycoconjugate carbohydrate residues, critically determines the specificity and strength of lectin-carbohydrate interactions $[7,10,11]$. Numerous synthetic multivalent glycopolymers and dendrimers displaying this effect have been developed for the targeting of cell/organ specific lectins for drug-delivery purposes and for the inhibition of cell-cell or cell-foreign body (bacteria/virus) interactions [10,12-14] .

The capacity of the hepatic asialoglycoprotein receptor (ASGP-R) to recognize terminal $\beta$-galactosyl and $\beta-N$-acetyl-galactosaminyl residues on desialylated glycoproteins [15] can be used for liver targeting of artificial glycoconjugates. This has been successfully achieved with galactose/lactosecontaining glycoconjugates, with a multivalence effect (tetra $>$ tri $>$ di $>$ mono) on liver uptake [16]. The functional imaging of liver ASGP-R is of both diagnostic and prognostic value during the treatment of liver pathologies (e.g., cancer and hepatitis B). Several hepatic imaging agents have been described that rely on macromolecular bioconjugates and polymer scaffolds as carriers, bearing efficient reporter groups and pendant $\beta$-galactoside and/or $N$-acetyl- $\beta$-galactosaminyl residues as targeting groups of the ASGP-R. A conjugate of a neoglycoprotein, galactosylated serum albumin (GSA), with [99m Tc]-DTPA, [99m $\mathrm{Tc}]-D T P A-G S A ~[17]$, has been used in single photon emission computed tomography (SPECT) hepatic imaging of rodents and humans to study liver pathologies [18-21]. The hepatocyte-specific nature of the ASGP-R and the fact that it is still expressed (although in reduced numbers) on hepatoma cells makes it possible to detect liver-cancer metastases to other organs, such as bone [22]. The [111 In]-DTPA-GSA analogue has also been used in mouse liver SPECT imaging [23].

Two classes of potential CAs for liver MRI through targeting of the hepatocyte ASGP-R have also been developed and tested in cells and mice:

- Macromolecular: a Gd-DTPA conjugate of polylysine (PL) derivatized with galactosyl groups (Gd-DTPA-gal-PL) [24] and a spin-labeled arabinogalactan [25];

- Particulate systems: monocrystalline iron oxide nanoparticles (MION) conjugated to the bovine plasma protein asialofetuin (ASF), MION-ASF [26];

- Arabinogalactan (AG)-coated ultrasmall superparamagnetic iron oxide particles (USPIO) (FIGURE 2) [27-30]. 
Both the macromolecular and particle-based ASGP-R-targeted imaging agents described above include carriers bearing multiple reporter groups and a multivalent display of galactosyl-targeting groups.

However, these agents have the drawback of being inherently polydisperse and ill characterised. Chemically well-defined, monodisperse and characterized multivalent agents can be assembled by an alternative molecular design: the conjugation of dendrimeric-clustered carbohydrate bifunctional reagents through spacers to an MRI reporter group. Various Gd(III) complexes of the DTPA- and DOTA-type ligands, peripherally substituted with one or more targeting group(s) consisting of a clustered carbohydrate of variable valence, with different topologies (Figure 3), containing an increasing number of terminal galactosyl (Gal), lactosyl (Lac) or glycosyl (Glc) groups, have been synthesized and studied [31-36]. The ligands included various DOTA monoamide derivatives (FIGURE 4), with one (DOTAGal, DOTAGlc and DOTALac; 9 ), two

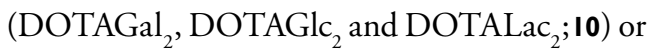
four $\left(\mathrm{DOTAGal}_{4} ; \mathbf{1 2}\right)$ terminal sugar groups, one DOTA cis-bisamide derivative with two terminal sugar groups (DO2A(cis) $\left.\mathrm{Gal}_{2} ; \mathrm{II}\right)$ and DTPA bisamides with two (DTPAGal ${ }_{2}$ and DTPALac ${ }_{2}$; 13) or four (DTPAGal ; 14) terminal sugar groups. All dendrimeric sugar units were bound thioglycosidically, in order to prevent them from being cleaved off by enzymes [32-35]. The ${ }^{1} \mathrm{H}$ nuclear magnetic relaxation dispersion (NMRD) profiles showed that the relaxivity increase of these compounds relative to the respective parent compounds without the sugar derivatives (Gd-DOTA; $\mathbf{2}$ and Gd-DTPA-BMA; $\mathbf{3}$ ) is much lower that that expected for their molecular weight increase [32,33]. As an example, at $20 \mathrm{MHz}$ and $298 \mathrm{~K}, \mathrm{r}_{1}$ of Gd-DTPALac ${ }_{2}$ is only $13 \%$ higher than that of Gd-DTPA-BMA, although its molecular weight is approximately three-times higher [33]. An evaluation of the parameters governing their relaxivity showed that $r_{1}$ of these Gd(III) complexes of glycoconjugate ligands is limited by:

- Slow water exchange (the residence time of water in the first coordination sphere, $\tau_{\mathrm{M}}$ is approximately $830 \mathrm{~ns}$ for Gd-DOTA derivatives and $\tau_{\mathrm{M}}$ is approximately $25 \mu \mathrm{s}$ for Gd-DTPA-BMA derivatives);

- Fast overall rotational dynamics; due to the high internal mobility of the sugar side chains and of the spacers that connect them to the

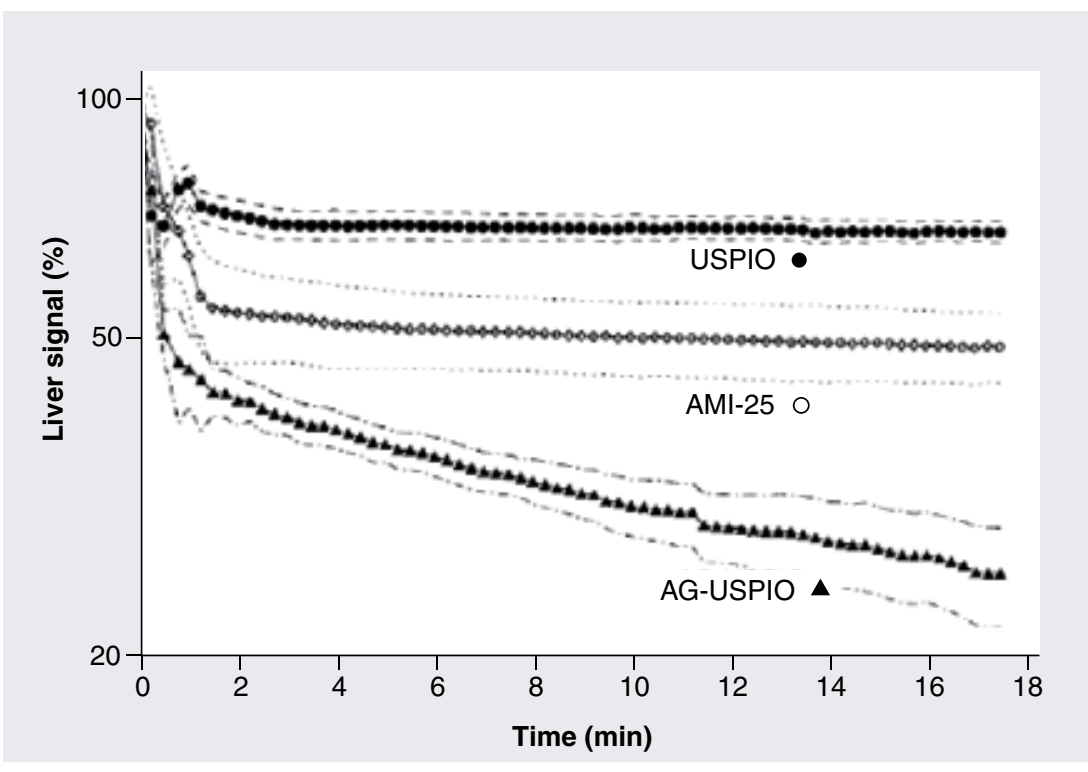

Figure 2. Dynamic changes in liver signal intensity for individual Sprague-Dawley rats after administration of the hepatocyte agent arabinogalactan-coated ultrasmall superparamagnetic iron oxide (USPIO) and the reticuloendothelial system agents USPIO and the superparamagnetic iron oxide formulation AMI-25 (Advanced Magnetics, Inc., MA, USA) at a dose of $\mathbf{1 0} \mu \mathrm{M} / \mathbf{k g}$ iron. Data were derived from dynamic echo-planar images. The data points represent the raw data from each of three experiments. The broken lines indicate plus and minus one standard deviation about the samples $(n=4)$ for each contrast agent.

Reproduced with permission from [30]. CJohn Wiley \& Sons, Inc.

(5)
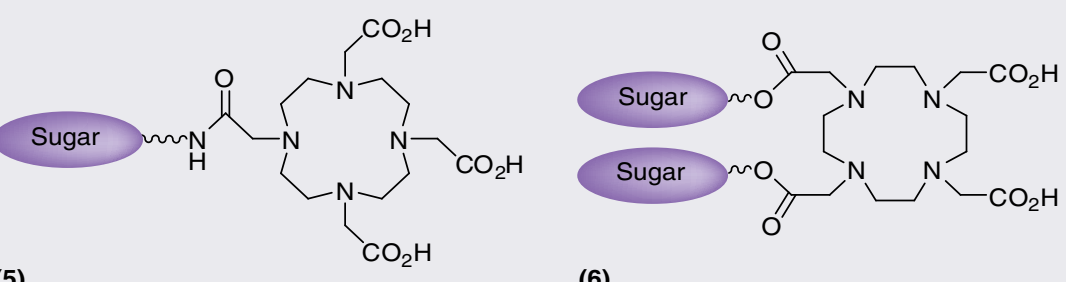

(6)

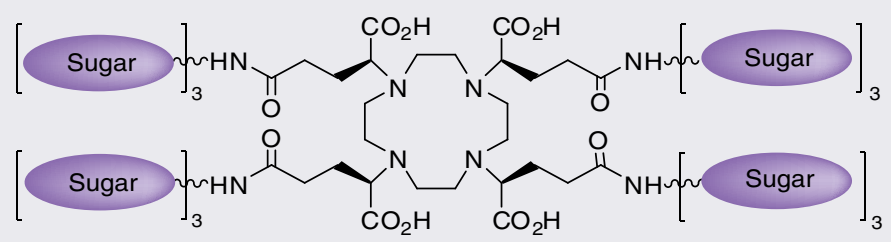

(7)

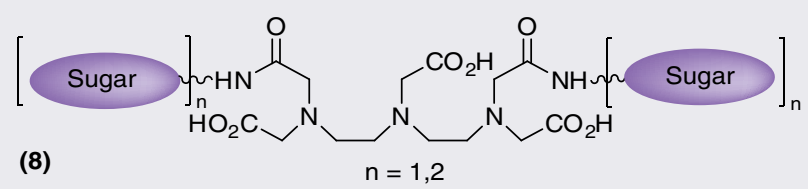

Figure 3. Comparison of the general topology of glycoconjugates of DOTA (5 -7) and DTPA (8) ligands.

Adapted with permission from [31]. 
ASIALOGLYCOPROTEIN RECEPTOR

Organ-specific heterooligomeric lectin that is only expressed at the surface of hepatocyte cells of the liver, it recognizes terminal b-galactosyl and b- $\mathrm{N}$-acetyl-galactosaminyl residues on desialylated glycoproteins. It is involved in selective removal of the glycoproteins, with those exposed terminal residues, from serum

\section{RELAXIVITY}

Relaxivity $\left(r_{1}\right.$ or $\left.r_{2}\right)$ of a contrast agent is the increase of relaxation rate $\left(I / T_{1}\right.$ or $I / T_{2}$, where $T_{1}$ and $T_{2}$ are the longitudinal and transverse relaxation times) of water protons per $\mathrm{mM}$ of contast agent more rigid part of the chelate, which are located at positions that do not allow an effective coupling between the $\mathrm{Gd}-\mathrm{OH}_{2}$ vector and the tumbling motion of the whole complex;

- Nonoptimal electron-spin relaxation due to their asymmetric Gd(III)-coordination cage $[32,33]$.

This new class of hydrophilic liver-targeted agents was evaluated in vivo by imaging techniques in Wistar rats and mice. In order to be able to compare the results for MRI with $\gamma$-imaging studies of the corresponding Gd(III) complexes, the ligands were complexed to the $\gamma$-emitting ${ }^{153} \mathrm{Sm}$ (III) nuclide [34,35]. The results show that the liver uptake of the labeled compounds depends on their valency, sugar type and topology. They are prime examples of the aforementioned cluster glycoside effect. After $24 \mathrm{~h}$ postinjection in Wistar rats, the compounds bearing four galactose residues clearly show a much better enrichment in the liver than the mono- or di-substituted systems, indicating that binding to the ASGP-R occurs in a multivalent fashion. The affinity decreases if lactose is attached and is at its lowest for the glucosederived compounds. The dendrimeric topology of DOTAGal ${ }_{2}$ has a higher targeting efficiency than that of the DO2A(cis) $\mathrm{Gal}_{2}$. Blocking the ASGP-R in vivo with the presence of its highaffinity ligand asiolofetuin (ASF)-reduced liver uptake by $90 \%$, strongly suggesting that the liver uptake of these compounds is mediated by their binding to ASGP-R.

However, despite the specific liver uptake of the radiolabeled galactosyl-bearing compounds, a dynamic contrast-enhanced (DCE) MRI assessment of the corresponding Gd(III) chelates in mice showed liver-to-kidney contrast effects that are not significantly better than those shown by Gd-DTPA [35]. This probably results from the quick wash-out from the liver of these highly hydrophilic complexes, before they can be sufficiently concentrated within the hepatocytes via receptor-mediated endocytosis.

Gd(III) complexes that combine a symmetrically substituted structure and a fast inner-sphere water exchange with an effective motional coupling, as described above, have been synthesized and studied (Figure 5) [36]. It concerns two types of Gd-DOTA complexes, $\alpha$-substituted at the four pendant acetate arms with dendrimeric sugar structures (15 \& 16), in which the Gd(III) ion lies at the barycenter of the macromolecular structure, so that it resides upon any axis of reorientational motion. These structures are based on the Gd(III) complex of DOTA, $\alpha$-substituted with tetra(carboxyethyl) groups at each of the four acetate arms, $(R, R, R, R /$ $S, S, S, S)-\left[\mathrm{GdgDOTA}\left(\mathrm{OH}_{2}\right)\right]^{5}$, which is known to have a fast water-exchange rate, connected through amide derivatization of the four terminal carboxylate groups of the $\alpha$-substituents to four trisaccharide dendritic wedge amine structures containing three $\beta$-glycosyl units. The connection of the chelate with the dendritic sugar occurs either directly ([GdgDOTA-Glu $\left.\mathrm{G}_{12}\left(\mathrm{OH}_{2}\right)\right]^{5}$; 15) or through glycine spacers ([GdgDOTA$\left.\mathrm{Glu}_{12} \mathrm{Gly}_{4}\left(\mathrm{OH}_{2}\right)\right]^{5-}$ ) (Figure 5; 16). These complexes (MW 3.2-3.45 kD) have much higher relaxivities than the Gd(III) complexes of the monoamide DOTA derivatives $(\mathbf{9}, 10 \& \mathbf{1 2})$ described above. An analysis of their variable temperature ${ }^{1} \mathrm{H}$ NMRD profiles and ${ }^{17} \mathrm{O}$ NMR $\mathrm{T}_{2}$ values [36] shows that this can be rationalized by:

- Optimized water exchange rate $\left(\tau_{\mathrm{M}} \sim 198\right.$ $221 \mathrm{~ns})$;

- Slow rotational dynamics due to their very compact and symmetrical structure;

- A high contribution to $r_{1}$ from water molecules in the second coordination sphere of Gd(III), hydrogen-bonded to the hydroxyl groups of the sugars.

In MRI experiments at $2 \mathrm{~T}$ with a mouse model of a mammary tumor expressing the HER-2/neu receptor, complex 15 showed a stronger and longer-lived signal enhancement of the tumor area compared with the commercial CA Gd-HPDO3A at the same dose, excretion primarily via the renal system, and no liver retention (Figure 6) [36]. However, this preliminary study did not assess the binding affinity of $\mathbf{1 5}$ to the HER-2/neu receptor in vitro. A similar MRI study undertaken with the $\beta$-galactosyl analogue of complex 16 [36] showed no significant signal enhancement of the liver, despite the presence of the 12 peripheral galactosyl units. These results may mean that this compound and compounds 9-14 are too hydrophilic to be efficiently concentrated within the hepatocytes via ASGP receptor-mediated endocytosis.

Prior to these studies, only a low-molecular weight, well-characterized, monomeric [111 In]-radiolabeled galactopyranosyl conjugate of DOTA for scintigraphic applications using the targeting of the ASGP-R both in hepatic cell lines and mice had appeared in the literature [37]. 


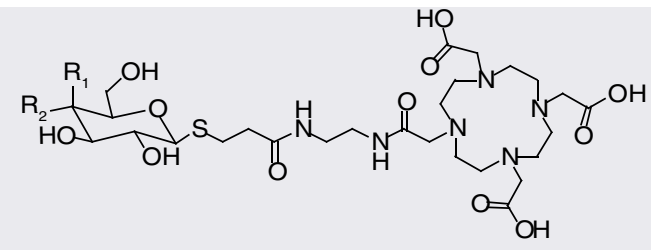

(9a) $\mathrm{R}_{1}=\mathrm{OH}$ and $\mathrm{R}_{2}=\mathrm{H}$-DOTAGal

(9b) $R_{1}=\mathrm{H}$ and $\mathrm{R}_{2}=$ OH-DOTA-Glc

(9c) $R_{1}=H$ and $R_{2}=\beta$-D-galactopyranosyl-DOTALac

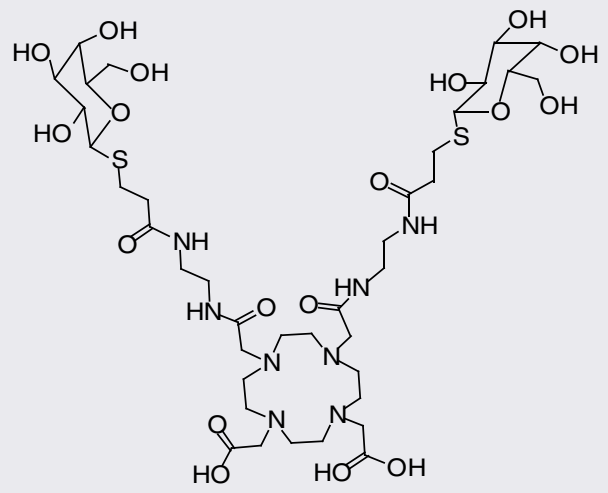

(11) $\mathrm{DO}_{2} \mathrm{~A}$ (cis) $\mathrm{Gal}_{2}$

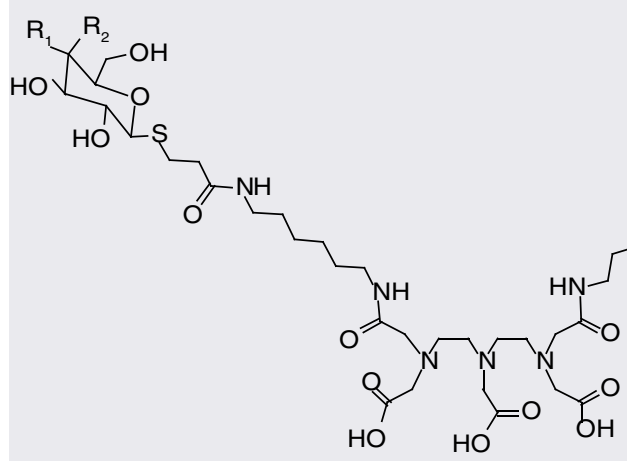

(13a) $\mathrm{R}_{1}=\mathrm{OH}$ and $\mathrm{R}_{2}=\mathrm{H}$-DTPAGal

(13b) $R_{1}=H$ and $R_{2}=\beta$-D-galactopyranosyl-DTPALac ${ }_{2}$<smiles>O=CCCSCCOC(O)C(O)CO</smiles>

(14) DTPAGal

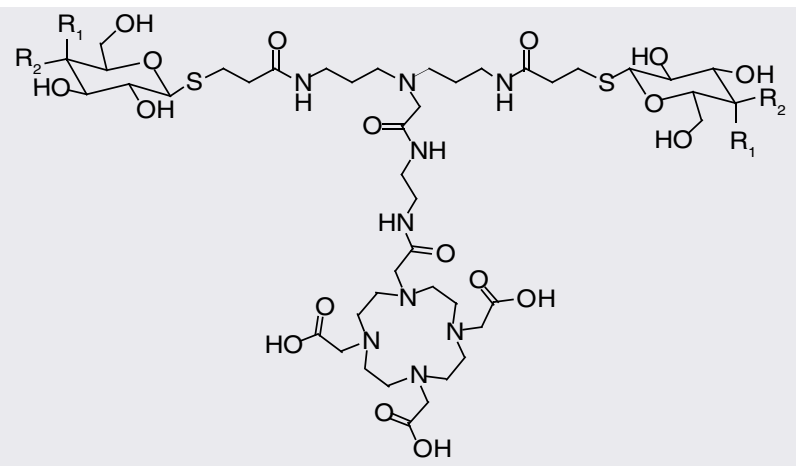

(10a) $\mathrm{R}_{1}=\mathrm{OH}$ and $\mathrm{R}_{2}=\mathrm{H}$ DOTAGal

(10b) $R_{1}=H$ and $R_{2}=\mathrm{OH}$ DOTAGlc ${ }_{2}$

(10c) $R_{1}=H$ and $R_{2}=\beta$-D-galactopyranosyl DOTALac ${ }_{2}$

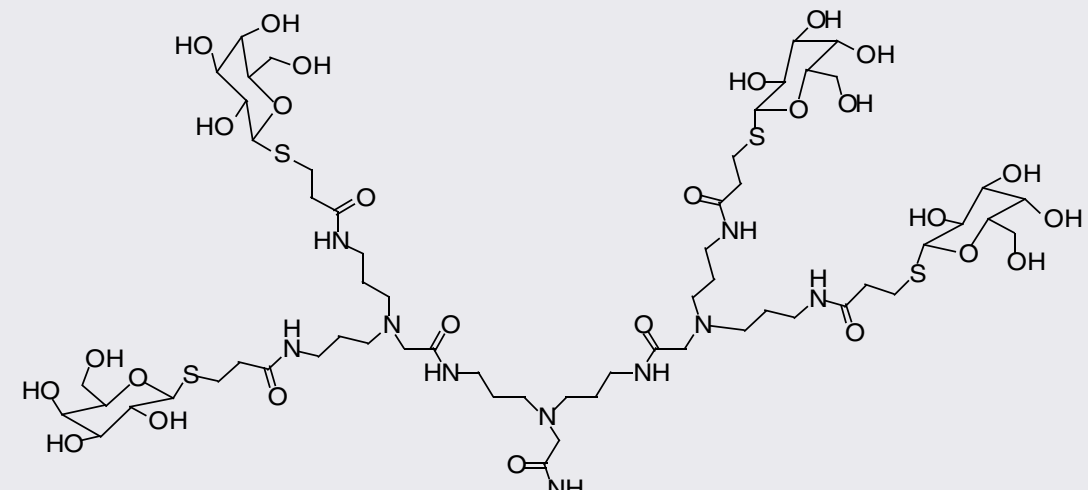

(12) DOTAGal $_{4}$<smiles>NCCNC(=O)CN(CCN1CCN(CC(=O)O)CCN(CC(=O)O)CC1)CC(=O)O</smiles><smiles>OC1C(O)C(O)C(O)C(O)C1O</smiles><smiles>OCC(O)C(O)CO</smiles>

$\mathrm{HO}$<smiles></smiles><smiles>CCSCC(O)C(O)C(O)C(O)O</smiles>

Figure 4. Glycoconjugated DOTA and DTPA amide derivative ligands used as Gd(III) complexes in MRI contrast agents studies. The ligands include: DOTA monoamide derivatives with one (9), two (10) or four (12) terminal sugar groups, one DOTA cis-bisamide derivative with two terminal sugar groups (II) and two DTPA bisamides with two (I3) or four (14) terminal sugar groups. 


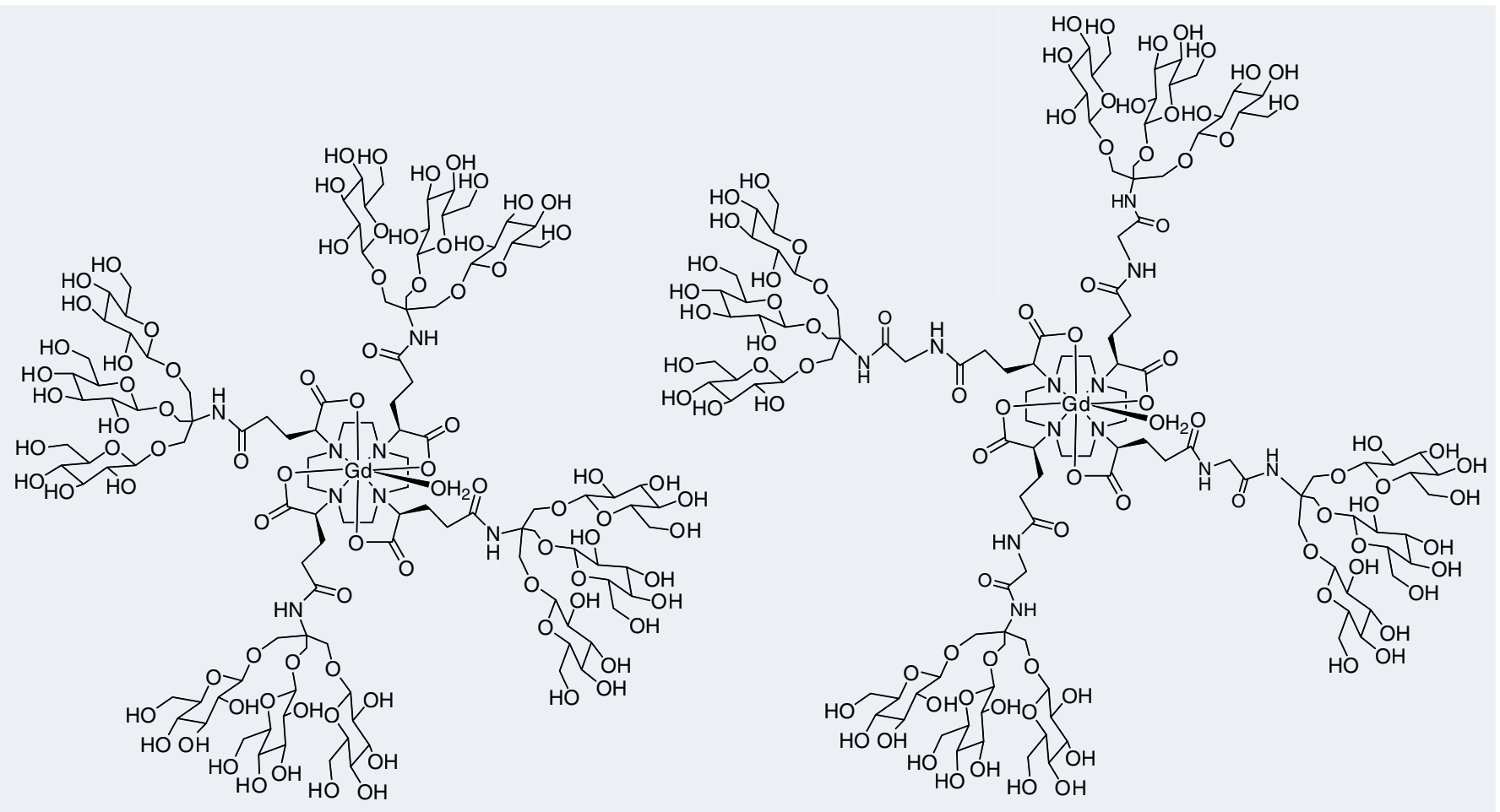

(15) $\left[\text { Gdg DOTA-Glu }{ }_{12}\left(\mathrm{OH}_{2}\right)\right]^{5}$

(16) [Gdg DOTA-Glu $\left.{ }_{12} \mathrm{Gly}_{4}\left(\mathrm{OH}_{2}\right)\right]^{5-}$

Figure 5. Two Gd(III) complexes of DOTA derivatives $\alpha$-substituted at the four pendant acetate arms with dendrimeric sugar structures $(15 \& 16)$ with optimal $\tau_{\mathrm{R}}$ values, thanks to the location of the $\mathrm{Gd}^{3+}$ ion on the barycenter of their macromolecular structure.

- Ln-chelates conjugated with Sialyl-Lewis $X$ mimics to target inflammation

Selectins are a family of adhesion molecules that mediate the initial attachment of leukocytes to activated endothelial cells in response to inflammation and tissue injury. Of the three closely related cell-surface selectins, L-selectin, P-selectin and E-selectin, the two latter selectins are expressed by vascular endothelial cells while L-selectin is expressed on leukocytes. Selectin expression is strongly induced by inflammatory mediators and the activated endothelial cells
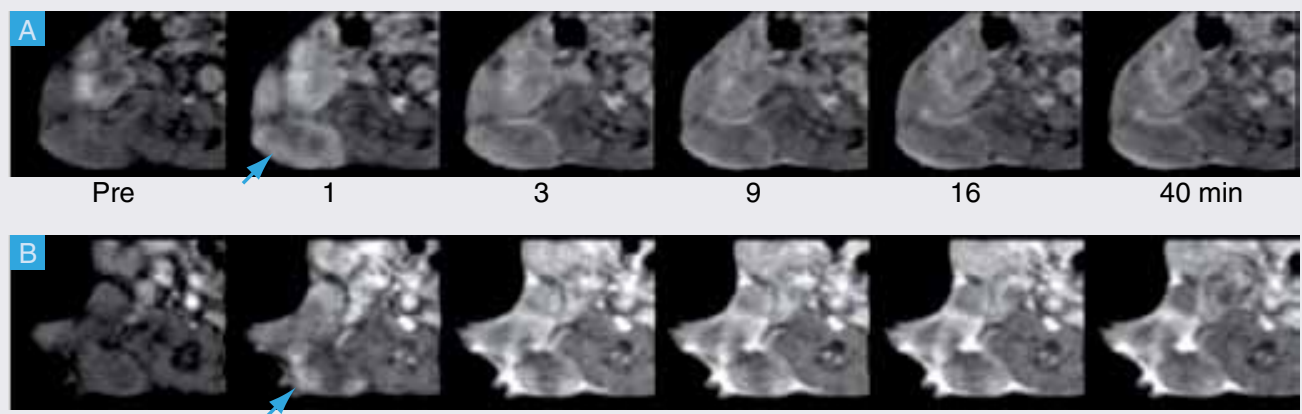

Figure 6. In vivo $\mathrm{T}_{1}$-weighted magnetic resonance images acquired in a mouse model of mammary carcinomas (BALB-neuT female mouse overexpressing the transforming activated rat $H E R-2 / n e u$ oncogene under the control of the mouse mammary tumor virus promoter) pre- and post-administration of 4 (Gd-HPDO3A) (A) or 16 (GdgDOTA$\left.\mathrm{Glu}_{12} \mathrm{Gly}_{4}\left(\mathrm{OH}_{2}\right)\right]^{5-}(\mathrm{B})$ at the same gadolinium dose $(0.1 \mathrm{mmol} / \mathrm{kg})$. The tumor-signal enhancement (arrow) was two-times higher with complex $\mathbf{1 5}$ than with $\mathbf{4}$, further highlighting tumor structures. The contrast caused by $\mathbf{1 5}$ showed also a slow wash-out.

Data from [Fulton Da, Elemento EM, Aime S, Chaabane L, Botta M, Parker D. Unpublished Data]. 
overexpress $\mathrm{P}$ - and E-selectins. Imaging selectins with MRI is challenging, due to their low abundance per voxel.

E-selectin is a cell-adhesion glycoprotein that is present in significant amounts on vascular endothelial cells 4-24 h after cytokineinduced transcription, following an injury in the body. The specific interaction of this selectin with the tetrasaccharide antigen Sialyl-Lewis X (sLe ${ }^{\mathrm{x}}$; FIGURE 7; 17), on the surface of monocytes, neutrophils, basophils, eosinophils, and a specific subset of T-lymphocytes plays an important role in inflammation and in many immune system mediated diseases including rheumatoid arthritis and cancer metastasis. Much research has been devoted to the design as well as the synthesis of sialyl mimetics, with the aim of using them as inhibitors of sLe ${ }^{x}$-E-selectin binding [38].
Molecular modeling based on the $\mathrm{x}$-ray structure of E-selectin and an NMR study of the conformation of bound $s \mathrm{Le}^{\mathrm{x}}$ has led to the rational design of a series of low-molecular weight mannose-based inhibitors with structure 18 [39]. This has inspired Muller et al. to synthesize the analogous derivative 19, which has an amino function that can serve as an anchor for its conjugation with paramagnetic reporter groups to form MRI CAs targeted to inflammation [40].

Reaction of 19 with DTPA-bisanhydride and subsequent complexation with Gd(III) produced conjugate 20 (Gd-DTPA-B $\left.\left(s \operatorname{Le}^{x} \mathrm{~m}\right) \mathrm{A}\right)$ [40]. The ${ }^{1} \mathrm{H}$ NMRD profile showed that the relaxivity of this compound is almost the same as that of the parent system Gd-DTPA, which is surprising since the molecular weight of Gd-DTPA-B $\left(s e^{x} m\right) A$ is higher [41]. An evaluation of the parameters

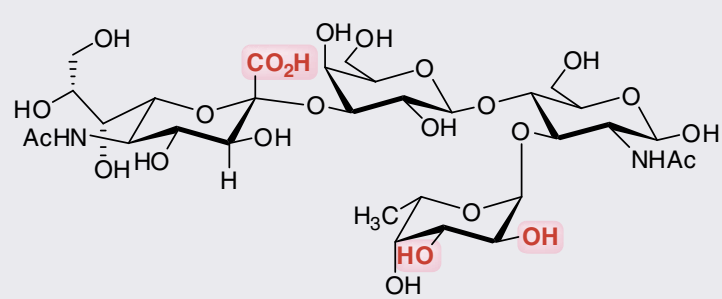

(17) $s L e^{x}$

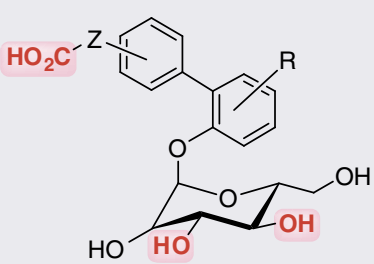

(18)

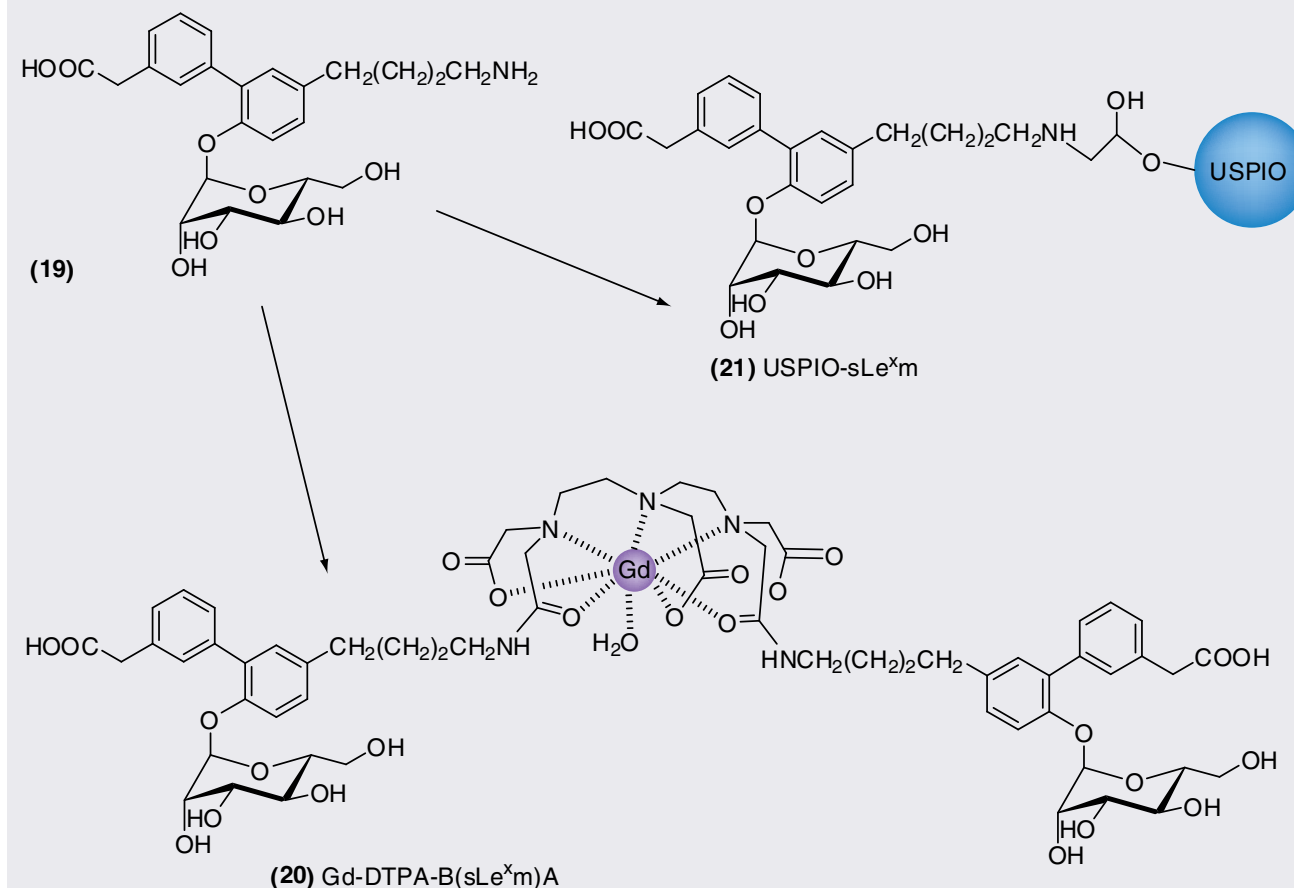

Figure 7. Comparison of the molecular structures of $s \mathrm{Le}^{\mathrm{x}}(\mathbf{1 7})$ and mimetics. Compounds 18

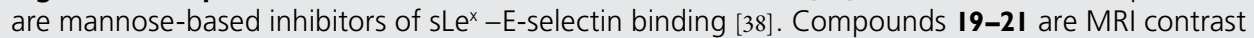
agents based on this inhibitor. Atoms in boxes are those involved in interactions with selectins. USPIO: Dextran-coated ultrasmall particle of iron oxide. 

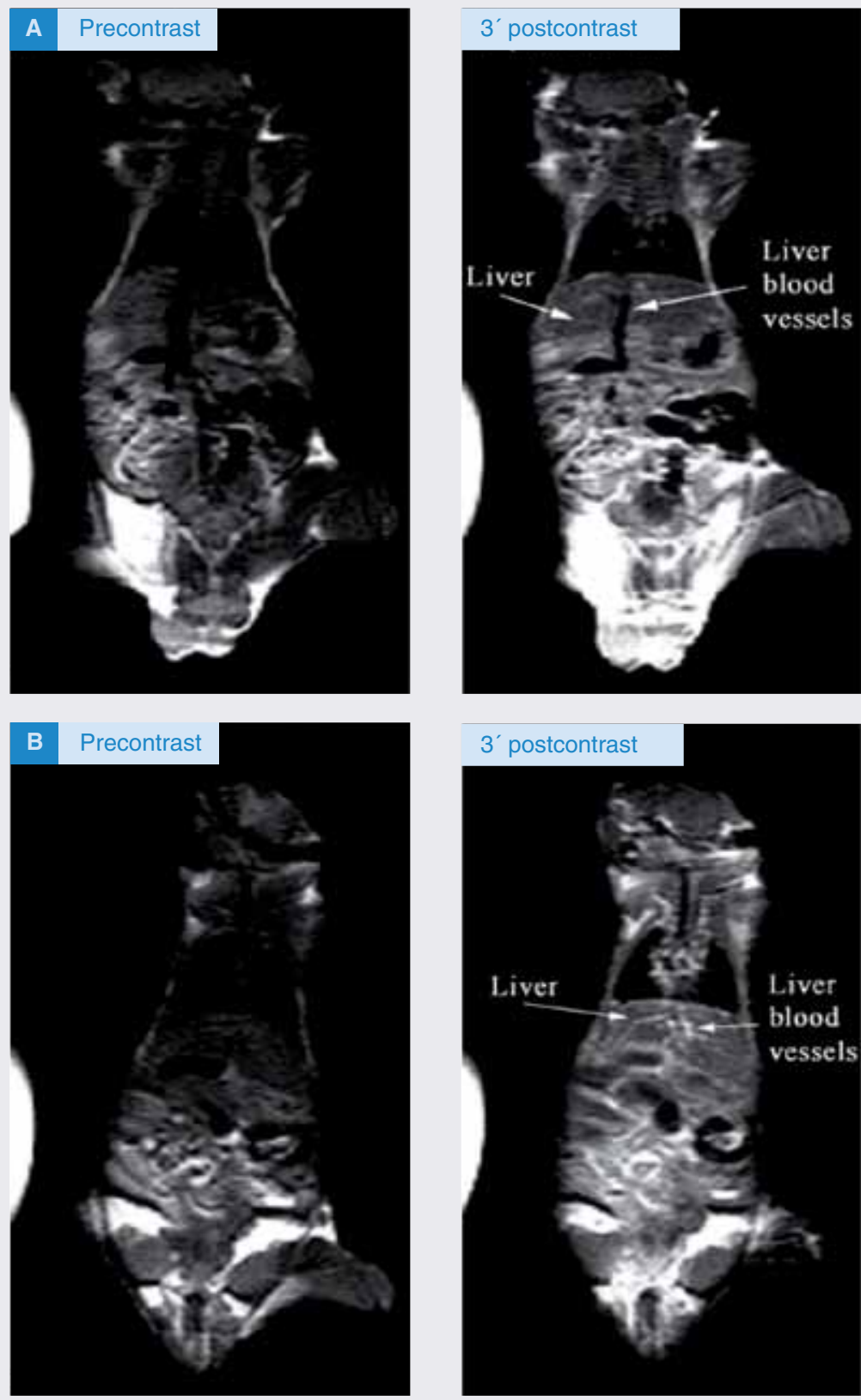

Figure 8. MR coronal images of a (A) healthy mouse and (B) a mouse with hepatitis before and after administration of Gd-DTPA-B(sLexm)A.

The images were obtained with a Siemens Magnetom Impact System at 1.0 T. Reproduced with permission from [42].

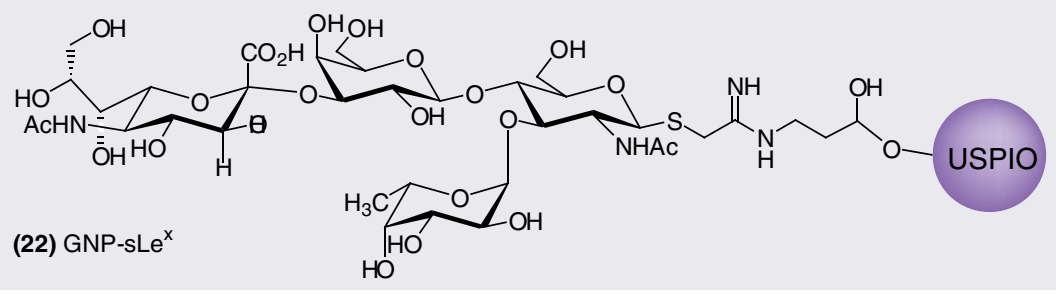

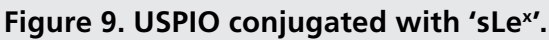

USPIO: Ultrasmall superparamagnetic particles of iron oxide. governing the relaxivity shows that the residence time of water in the first coordination sphere $\left(\tau_{\mathrm{M}}\right)$ is not limiting the relaxivity. The unexpected low relaxivity might be the result of a relatively large distance between Gd(III) and the protons of the Gd-coordinated water molecule. Transmetallation experiments showed that Gd-DTPA-B $\left(s L e^{x} m\right) A$ is kinetically less stable than Gd-DTPA, but more stable than the commercial Gd-bisamide complex, Gd-DTPA-BMA. Furthermore, Gd-DTPA-B(sLe ${ }^{x}$ m)A has no significant interaction with human serum albumin (HSA) and, therefore, competition of HSA during the targeting of E-selectin does not occur [41].

The performance of the CAGd-DTPA-B $\left(\mathrm{sLe}^{\mathrm{x}} \mathrm{m}\right)$ $A$ has been evaluated by in vivo pharmacokinetic and biodistribution studies on mice and rats in a fulminant hepatitis model [42]. A high specificity for E-selectin was confirmed by a significant and prolonged contrast enhancement between blood vessels and parenchyma in pathological conditions (FIGURE 8). The biodistribution of the compound showed its retention in inflamed liver and spleen by both specific mechanisms and accumulation due to necrotic lesions. The sialylmimetic 19 has also been grafted to the dextran coating of USPIO to give 2I (USPIO-sLe ${ }^{\mathrm{x}} \mathrm{m}$ ) [43]. Tests of the resulting new $\mathrm{T}_{2} \mathrm{CA}$ on cultured human umbilical vein cells (HUVECs) stimulated to express inflammatory adhesion molecules, showed that the nanoparticles recognized endothelial E-selectin. In vivo tests using $\mathrm{T}_{2}$-weighted images of healthy mice showed loss of intensity of the liver signal, since USPIOs are known to pass through the fenestrae of the liver and to be captured by Kupffer cells. On the contrary, a mouse model of hepatitis gave images with a significantly lower attenuation of the liver intensity, which suggests that the CA is retained extracellularly by selective interaction with endothelial E-selectin. Recently, the same mimetic was also coupled to carboxylated USPIOs that were coated with PEG to prolong the plasmacirculation time and to minimize the nonspecific accumulation of the particles in tissues [44]. The mean absolute concentration of iron oxide in inflamed muscles after injection of these particles was determined both ex vivo and in vivo by EPR. The efficacy of the grafted particles was improved by a factor of two, compared with the ungrafted particles. This was confirmed by a higher signal loss in MRI after administration of the grafted particles. Thus, USPIO-sLe ${ }^{x} m$ particles may be very suitable for the MRI diagnosis of inflammation and for the in vitro evaluation of endothelial cell activation. 


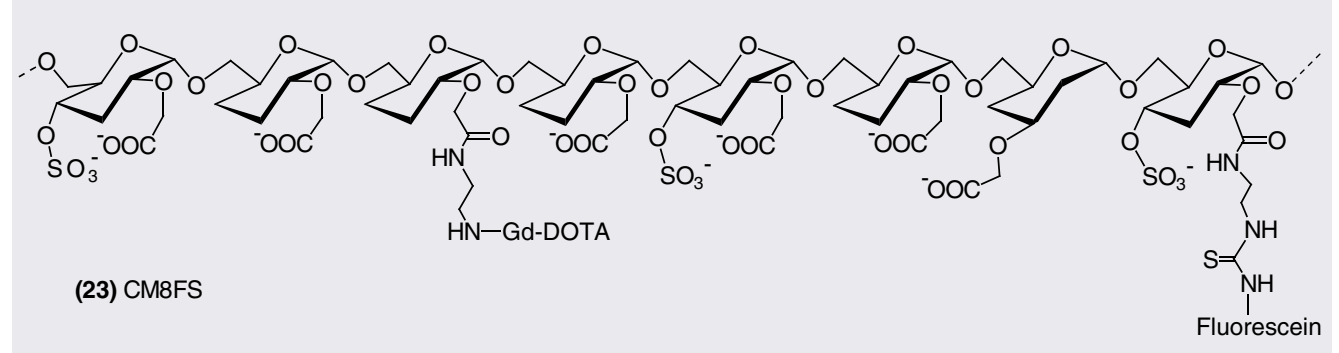

Figure 10. P-selectin glycoprotein ligand-1 mimetic CM8FS. Unsubstituted OH functions of the dextran backbone are omitted for clarity.

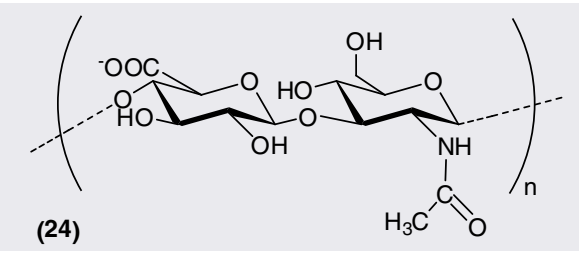

Figure 11. Hyaluronan.

This type of agent is also very promising for the early detection of endothelial activation in brain inflammation. They are able to detect E-selectin on the 'blood side' of the blood-brain barrier, which is indicative of a lesion on the 'brain side'. The principle was shown for Gd-DTPA-B $\left(s L e^{x} m\right) A$, which gave a modest signal enhancement for activated endothelium in the brain $[45,46]$. The aselective CA Gd-DTPA-BMA did not result in enhancement under the same conditions, showing that the blood-brain barrier was still intact. Van Kasteren et al. have synthesized a series of dextran-coated iron oxide nanoparticles, decorated with oligosaccharides of increasing carbohydrate complexity [47]. It appeared that only the nanoparticles conjugated with sLe $e^{\mathrm{x}}$ itself, (GNP-sLe ${ }^{\mathrm{x}}$; Figure 9; 22) targeted activated brain endothelium. With clinically relevant animal models, it was demonstrated that these particles are very sensitive negative CAs for early detection of endothelial activation by brain disease events. The lesions in question were not detectable with conventional MRI.

Another glycoprotein playing a role in inflammation is P-selectin, which is mainly expressed on the surface of activated platelets in, for example, cardiovascular diseases such as atherosclerosis and aneurism. Its main ligand is the sialomucin P-selectin glycoprotein ligand-1 (PSGL-1) expressed on the surface of lymphocytes. The recognition also involves the sLe ${ }^{\mathrm{x}}$ structural motif and, in addition, three sulfated tyrosine residues in the protein backbone. Chaubet et al.
A

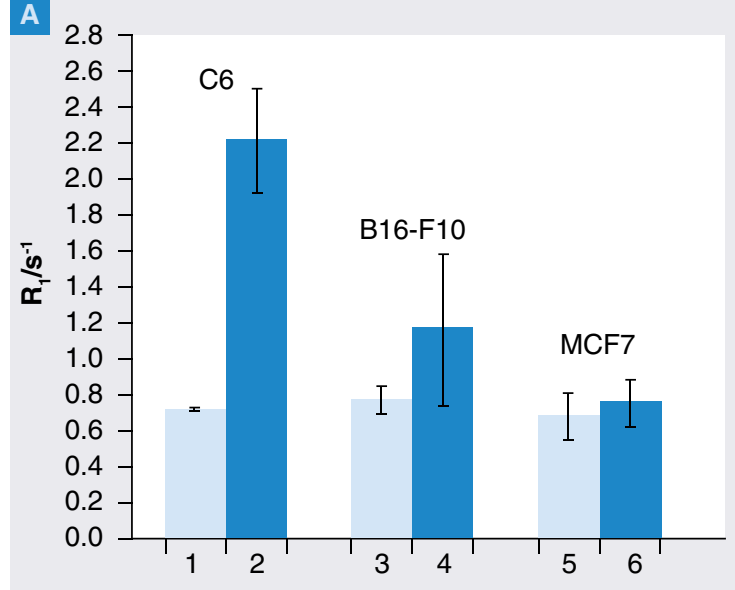

B

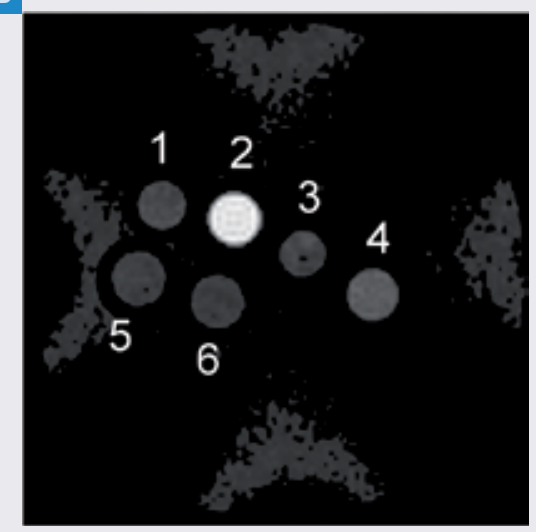

Figure 12. (A) ${ }^{1} \mathrm{H}$ relaxation rates of cellular pellets of human cell lines $\mathrm{C} 6$ (I \& 2), B16-F10 (3 \& 4) and MCF-7 (5 \& 6) after incubation at $37^{\circ} \mathrm{C}$ for $30 \mathrm{~min}$ in the presence of cationic liposomes (light blue bar) and in the presence of the these liposomes after functionalization with an excess of hyaluronan (dark blue bar). (B) Corresponding $T_{1}$-weighted MR image of a phantom containing cellular pellets after incubation in the presence of cationic liposomes $(\mathbf{I}, \mathbf{3} \boldsymbol{\&} \mathbf{5})$ or hyaluronanfunctionalized cationic liposomes (2, 4 \& 6).

Reproduced with permission from [49]. 


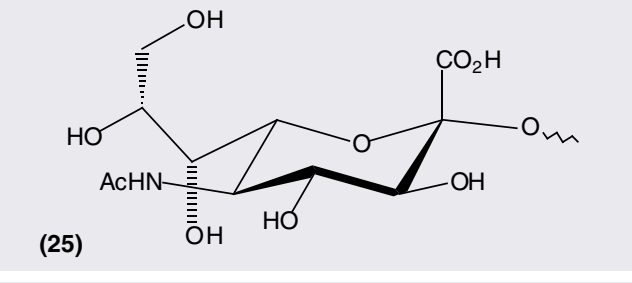

Figure 13. Neu5Ac end group in glycoconjugates.

have synthesized a mimetic for PSGL-1, consisting of a polydextran backbone (MW 27000) grafted with carboxymethyl groups (degree of substitution $[D S]=0.84$ per anhydroglucose unit), sulfate functions ( $D S=0.41$ ), Gd-DOTA chelates (DS $=0.08)$ and a fluorescein isothiocyanate fluorolabel $(\mathrm{DS}=0.008 ; \mathrm{CM} 8 \mathrm{FS}$; Figure 10; 23) [48]. Cytometry experiments on whole human blood and on platelets showed that the probe preferentially binds to activated platelets. No binding to other blood cells or resting platelets was observed. Furthermore, activated platelets incubated with CM8FS produced a bright MRI signal.

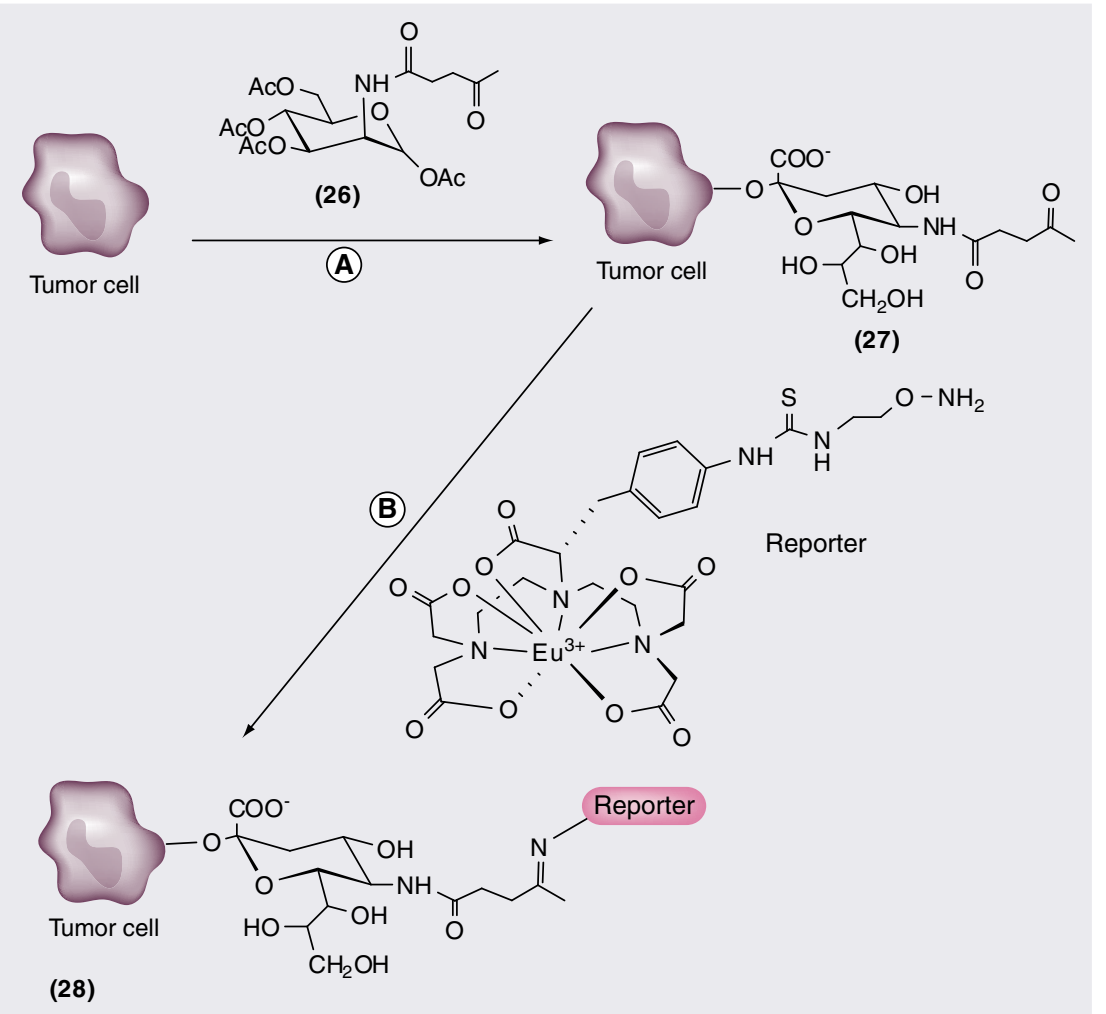

Figure 14. Strategy for the selective targeting of MRI contrast agents to highly sialylated cancer cells by means of cell surface engineering.

(A) Incubation of the tumor cells with peracetylmannose derivative $\mathbf{2 6}$ gives metabolically modified sialic acid $\mathbf{2 7}$ at the surface. (B) The ketone group at the modified surface is exploited for anchoring of the Eu(III) reporter through the formation of Schiff base $\mathbf{2 8}$
- Hyaluronan as a targeting vector for CD44 receptors

CD44, a receptor for hyaluronan, (HA; Figure II; 24), is expressed in a variety of tumors such as breast, colon, intestinal, and brain, as well as melanoma, basal cell carcinoma and stem cells. Aime and coworkers designed and prepared a supramolecular adduct of anionic hyaluronan and cationic liposomes loaded with Gd-HPDO3A [49]. Tumor cell lines (C6, B-16-F10 and MCF-7) showed rapid uptake through receptor-mediated endocytosis, which could be visualized with MRI (FIGURE I2).

\section{- Targeting of sialic acid at surfaces of cancerous cells with Ln chelates conjugated with phenylboronic acids}

Sialic acids are known to be overexpressed on tumor cells, where they are present as terminal groups on oligosaccharide chains of glycolipids and glycoproteins [50,51]. This phenomenon is related to the growing and spreading of the tumor. The sialic acid expression on tumor cells is approximately 1000 times higher than on healthy cells and, therefore, sialic acid is a good biomarker for the detection of cancer. Sialic acids comprise a family of 43 acidic 9-carbon sugars of which $N$-acetylneuraminic acid, (Neu5Ac, Figure 13; 25), is the most common one. In glycoconjugates, it is usually $\alpha(2,3)$ - or $\alpha(2,6)$ linked to galactose, galactosamine or to another sialic acid unit. Bertozzi and co-workers have exploited the sialoside biosynthetic pathway to metabolically modify naturally expressed sialic acid on human cells with a levulinoyl side chain (Figure I4; 27). The terminal ketone group of the latter function was then utilized as a chemical target for covalent binding with the aminooxy anchor conjugated with Eu-DTPA chelate. [52]. By luminescence, it was demonstrated that $10^{6}$ Eu chelates were targeted to normal Jurkat cells. A similar approach using the Gd analog might enable molecular imaging with MRI.

Neu5Ac is a structurally exceptional sugar unit in naturally occurring glycoconjugates because it has an exocyclic polyol function. This peculiarity can be exploited for its molecular recognition by boronates. Boronates can reversibly and covalently bind diol functions under the formation of five- and six-membered boronate esters [53]. The stability of these esters is for the greater part determined by their steric strain. Consequently, exocyclic diol functions, usually give rise to more stable esters. By ${ }^{11} \mathrm{~B}$ and ${ }^{13} \mathrm{C}$ NMR studies on 2-O-methyl Neu5Ac, it 


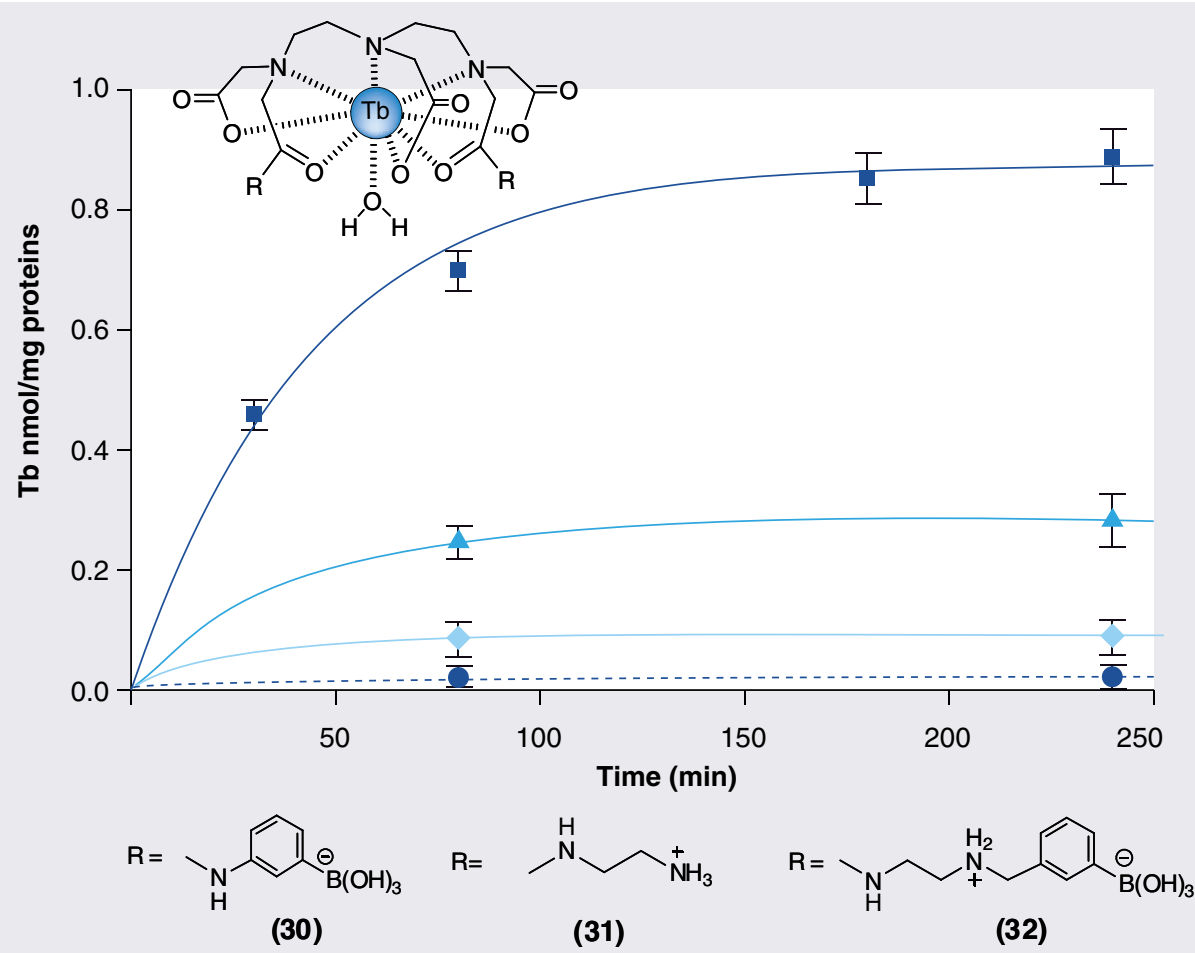

Figure 15. Interaction kinetics of $0.1 \mathrm{mM}$ solutions of ${ }^{160} \mathrm{~Tb}$ complexes of 29 (circle), 30 (triangle), 31 (diamond) and 32 (square) with $2.5 \times 10^{5}$ human glioma brain tumor cells (U-251 MG) for $4 \mathrm{~h}$ at $37^{\circ} \mathrm{C}$ in PBS medium. has been shown that, under physiological conditions, only weak but selective binding of the $\mathrm{OH}$ functions of the pendant arm of this compound occurs [54]. Based on these ideas, several conjugates of Gd-DTPA were designed for the targeting of sialic acid residues [55]. Compounds 30-32 were selected for labeling studies on tumor cells [55,56]. Compound $\mathbf{3 0}$ has a phenylboronic acid group for interaction with Neu5Ac, $\mathbf{3 1}$ has an $\mathrm{NH}_{3}{ }^{+}$function that can interact electrostatically with its $\mathrm{COO}^{-}$function, and $\mathbf{3 2}$ combines both structural features. Molecular modeling showed that the simultaneous interaction of the boronate and the $\mathrm{NH}_{3}{ }^{+}$in $\mathbf{3 2}$ is sterically feasible [54]. A gamma counting study on human glioma cells $\left(2.3 \times 10^{15} \mathrm{moles} / \mathrm{cell} \mathrm{Neu} 5 \mathrm{Ac}\right)$ incubated with the radioactive ${ }^{160} \mathrm{~Tb}$ complexes of $\mathbf{3 0 - 3 2}$ and of 29 ( ${ }^{160} \mathrm{~Tb}$-DTPA) showed that the kinetics of the increase of cell-associated activity shows the order $\mathbf{3 2}>>\mathbf{3 0}>\mathbf{3 1}>\mathbf{2 9}$ (Figure 15), which confirms the synergistic binding of Neu5Ac by the phenylboronate and ammonium functions. The essential role of Neu5Ac was demonstrated by an experiment in which the Neu5Ac at the glioma cell surface was enzymatically removed by sialidase. After treatment, the ${ }^{160} \mathrm{~Tb}$ complexes no longer recognized the cells. Comparison of the binding of the ${ }^{160} \mathrm{~Tb}$ label with human glioma tumor cells incubated with increasing concentrations of the ${ }^{160} \mathrm{~Tb}-32$ complex at $37^{\circ} \mathrm{C}$ with that at $4^{\circ} \mathrm{C}$ suggests that a considerable amount of the complex is taken up by cells at $37^{\circ} \mathrm{C}$ (Figure 16). Inductively coupled plasma atomic emission spectroscopy (ICP-AES) of lysates of the cells showed that the molar ratio terbium: boron is 1:1 rather than $1: 2$, as should be expected from the molecular structure of $\mathrm{Tb}-\mathbf{3 2}$. This indicates that a significant amount of $\mathrm{Tb}(\mathrm{III})$ is dissociated from the complex at the cell surface, which is in agreement with the known relatively low kinetic stability of Gd-DTPA-bisamide complexes. Previously, poor stability of another Gd-complex of a DTPA-bisamide, Gd-DTPA-BMA, was observed in cell experiments [57].

\section{Physiologically responsive probes \\ - Sugar sensing with the use of MRI}

Quantification of the extent of glycation of HSA and hemoglobin provides a record of average mid- and long-term blood-sugar concentrations [58], respectively. This is very useful for the management of diabetes [59]. In the presence of excessive levels of glucose (in diabetes patients),
RESPONSIVE CONTRAST AGENTS Category of targeted MRIcontrast agents that are able to act as reporters of the biological environment where they are distributed through parameters such as, for example, $\mathrm{pH}$, partial oxygen pressure, degree of glycation of proteins, concentration of $\mathrm{Ca}^{2+}$ and presence of enzymes 


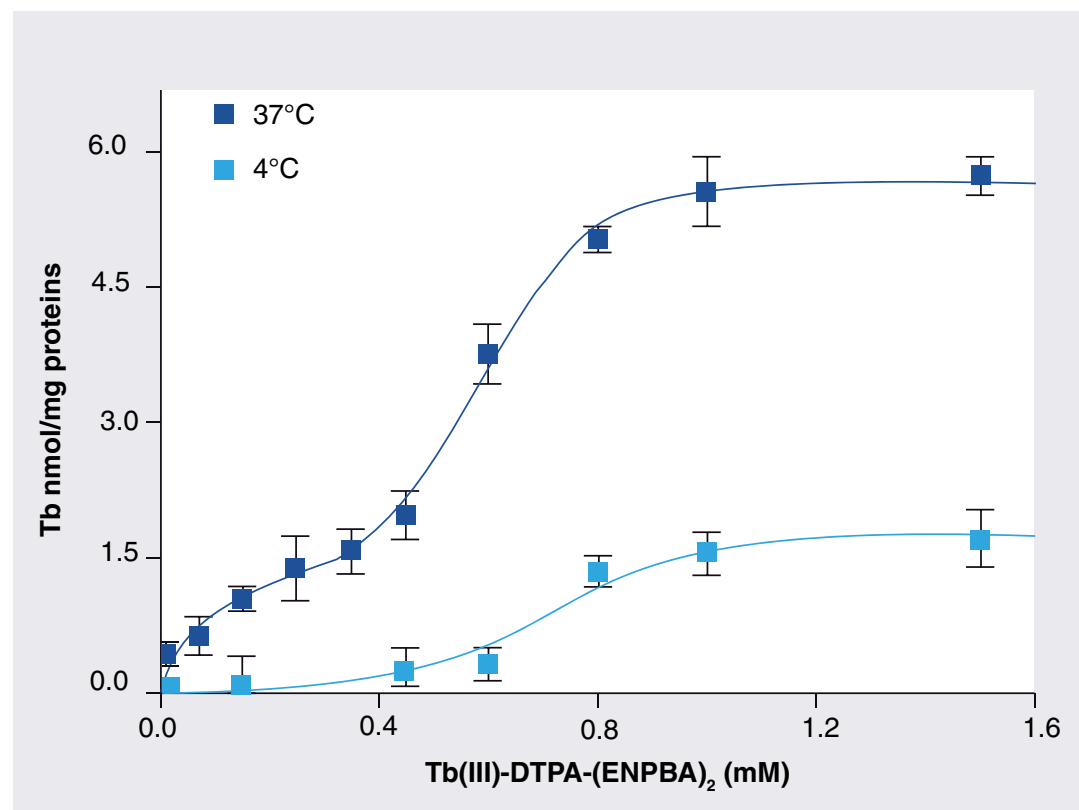

Figure 16. Binding of ${ }^{160} \mathrm{~Tb}$ label by human glioma tumor cells as observed upon incubation with various concentrations of 32 (Tb(III)-(ENPBA $\left.{ }_{2}\right)$ ) for $200 \mathrm{~min}, 5 \times 10^{5}$ cells used. was greater than ten. The conjugate of phenylboronate and Gd-DTPA, (Gd-DTPA-BPBA; Figure 18; 37), has been applied as a responsive MRI CA for glycated HSA [61]. Binding of the boronic functions of Gd-DTPA-BPBA to the syndiol moieties of the fructosamine residues in glycated albumin, as described above, induces an enhancement of the water proton relaxation rate as a consequence of the increased rotational correlation time, $\tau_{\mathrm{R}}$. In this way, it is possible to map the glycation level of proteins in the blood (Figure 18).

A similar mechanism of interaction was observed for fructosamine model compounds with a conjugate of phenylboronic acid and a lanthanide DTPA derivative, in which the central pendant arm was replaced by the methylamide of L-lysine [62]. Unfortunately, this complex also shows a rather strong interaction with hexosefree HSA and, therefore, is not suitable for the determination of the degree of glycation of HSA.

Unexpectedly, the Gd-DTPA-BPBA complex was strongly bound by unglycated oxygenated human hemoglobin [63]. This interaction involves formation of coordinative N-B bonds at two histidine residues of different $\beta$-chains of the peptide. The interaction of the Gd(III) complex with hemoglobin is site specific and results in a conformational switch (from the low-affinity [T] to the high-affinity $[R]$ state) in the tetrameric protein.

Sherry and co-workers have studied the interactions of a series of $\mathrm{Eu}$ (III) complexes of cyclen-based mono- and bis-(phenylboronate) ligands with glucose, galactose, fructose and lactose. The distance between the pendant boronate arms appears to be an important factor in determining the affinities for the various saccharides. The 1,7-disubstituted derivative 38 (Eu-DOTAM-2M-2PB; Figure 19) had a high and selective binding affinity for glucose (apparent stability constant of the resulting boronate ester: $339 \pm 29 \mathrm{M}^{-1}$ at $\mathrm{pH}$ 7) [64,65]. The glucose free glucose shows that the ratio of the resulting
phenylboronate esters of fructosamine and glucose

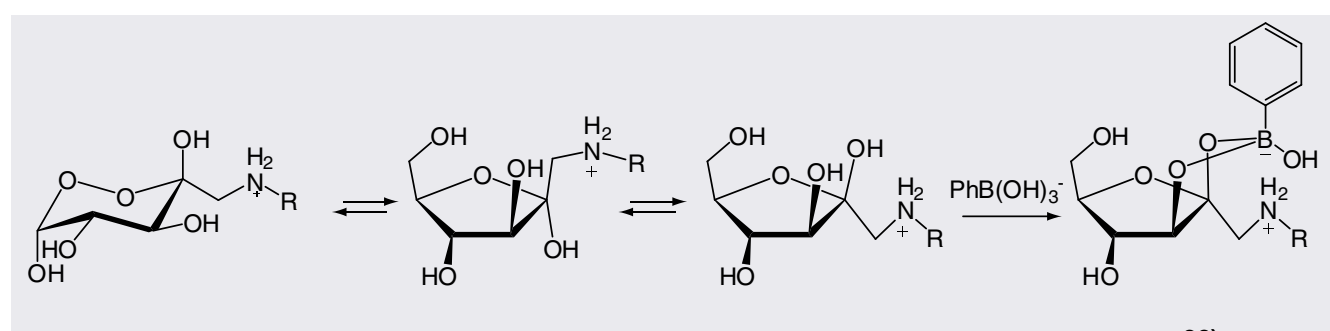

(33) $\beta$-pyranose (58\%)

(34) $\alpha$-furanose (19\%)

(35) $\beta$-furanose (24\%)

(36)

Figure 17. Anomeric equilibrium of glycated human serum albumin and its phenylboronate ester.

R: Human serum albumin 


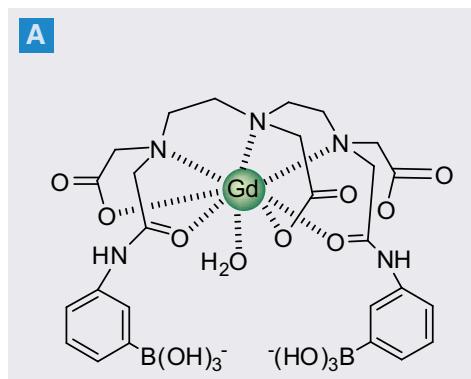

(37) Gd-DTPA-BPBA

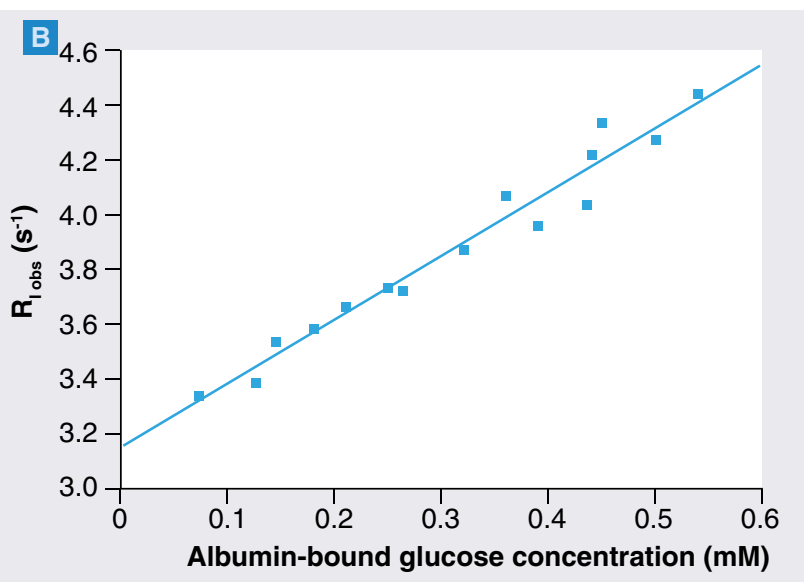

Figure 18. (A) $37 \mathrm{Gd}$-DTPA-BPBA and (B) the water proton relaxation rates of $0.56-\mathrm{mM}$ solution of 37 as a function of the millimolar concentration of glycidic groups on human serum albumin. is bound to the complex in a $1: 1$ fashion by forming a bridge above the Eu(III)-bound water molecule (Fıgure 19). Upon encapsulation with glucose, the exchange of the Eu(III)bound water and the bulk water slows down by a factor of two. The exchange rate then is sufficiently slow on the NMR time scale to permit presaturation of the ${ }^{1} \mathrm{H}$ resonance of the $\mathrm{Eu}(\mathrm{III})$ bound water resonance, in order to modulate the intensity of the bulk water through paramag. netic chemical exchange saturation transfer (PARACEST) and, thus, the contrast in an MR image. Therefore, this system can be used for the imaging of the tissue distribution of glucose. This has been demonstrated by CEST images of livers perfused in the magnet [66]. The CEST images responded to the glucose concentrations, which were altered by stimulation of glycogenolysis by the hormone glucagon, for example (Figure 20).

The binding strength of the system to glycated HSA is of the same order of magnitude as that of glucose. Since the plasma concentration of this material is normally relatively low, this should not interfere with the use of the complex as a glucose sensor. On the other hand, the good affinity for glycated HSA allows the in vitro determination of the degree of glycation in serum, using MRI and high-throughput methods [65].

It should be noted that Eu-DOTAM-2M-2PB is a positively charged compound. Positively charged lanthanide complexes are toxic for in vivo studies, which was confirmed by initial injections into mice [66]. A modified sensor with additional negatively charged carboxyl groups on the nonfunctional amide side chains has been reported to have similar CEST sensitivity to glucose and no clinical signs of toxicity in mice [67].

\section{- Detection of enzymatic activity by MRI}

Increased activity of certain enzymes has been described as an indication of the progression of many types of cancer. The methods used to measure this activity are, however, often difficult to
Paramagnetic chemical EXCHANGE SATURATION TRANSFER

Alteration of the magnetic resonance (MR) image contrast by taking advantage of chemical species that exchange protons with bulk water via a chemical exchange saturation transfer usually concerns the mobile $\mathrm{NH}$ protons of, for example, the ligands of a lanthanide complex<smiles>CNC(=O)CN(CCN)CCN(CCNC(=O)CN(CCNC(=O)Nc1cccc(B(O)O)c1)CC(=O)Nc1cccc(B(O)O)c1)CC(=O)NC</smiles>

(38) DOTAM-2M-2PB

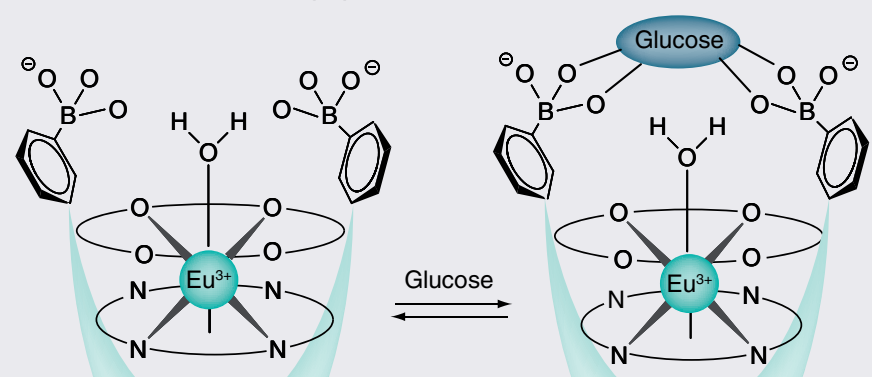

(39)

(40)

Figure 19. DOTAM-2M-2PB (38) and of the proposed binding model for its Eu(III) complex with glucose (39\& 40). 

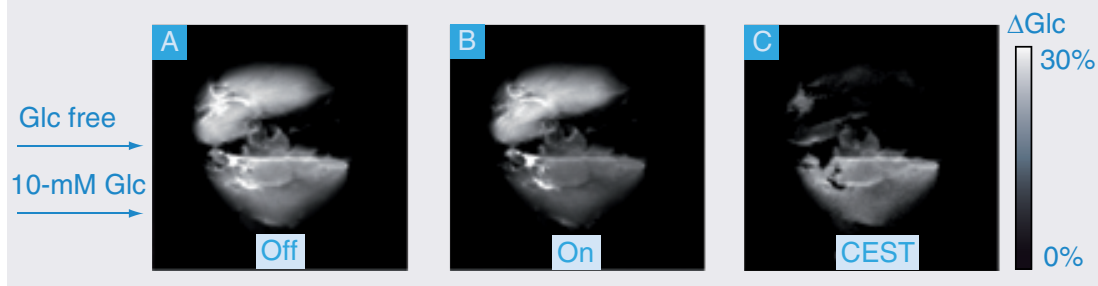

Figure 20. CEST images of fed mouse liver (top) perfused with 10-mM Eu-DOTAM-2M-2PB agent in the presence (fed liver) and absence (fasted liver) of $10-\mathrm{mM}$ glucose, $37^{\circ} \mathrm{C}$. (A) The 'off-resonance' image showed no contrast between the two livers while (B) the 'on-resonance' image showed darkening of fed liver versus the fasted mouse liver. (C) The CEST image showed the glucose-induced CEST contrast between the fed and the fasted mouse livers. CEST: Chemical exchange saturation transfer.

Reproduced with permission from [66]. employ in biological environments. This stimulates the search for physiologically responsive probes that can be activated to report on the metabolic state of cells and organs by MRI. The first example of a biologically activated CA consisting of Gd-HPDO3A conjugated to a $\beta$-galactose moiety (4I) was reported by Meade and co-workers already some years ago (Figure 21) [68]. Initially, $\beta$-galactose was serving as a steric obstacle for water molecules to enter the inner coordination sphere at the metal center $(q=0)$. After cleavage of the sugar by the enzyme $\beta$-galactosidase, the hydroxyl group becomes available for coordination of Gd(III) and the open space allows one water molecule to enter the coordination cage $(q=1)$, with a $20 \%$ increase in relaxivity as a consequence. This 'switching on' of the MRI activity of the CA was then used to monitor $\beta$-galactosidase activity, as this enzyme is commonly used as a marker to follow the regulation of individual genes, such as in transgenic animals. Compound $\mathbf{4 2}$ was shown to be useful for in vitro and in vivo (Xenopus laevis embryos) visualization and localization of gene expression by MRI [69]. However, results from the biodistribution of the analogue ${ }^{111} \operatorname{In}(\mathrm{III})$ radiolabeled compound in mice revealed that most of the tracer was located in the liver (taken up by ASGP-R) already, $2 \mathrm{~h}$ postinjection [37]. This approach was further exploited in the development of in vitro assays for the determination of the activity of $\beta$-glucuronidase [70], an enzyme with enhanced extracellular concentration around tumors and involved in the liberation of $\beta$-glucuronic acid during the mono-prodrug therapy. For this purpose, the Gd-DO3A chelate was conjugated with a $\beta$-glucuronic acid moiety, via a self-immolative nitrodihydroxybenzyl linker. Enzymatic hydrolysis of $\beta$-glucoronic acid triggers a cascade reaction that releases the $\mathrm{Gd}$ chelate, the bridging arm and $\mathrm{CO}_{2}$, changing the hydration number from 0 to 1 and, thus, increasing relaxivity.

This work has inspired Tóth and co-workers to design an enzyme-responsive CA for PARACEST application [71]. Benzylocarbamate was used as a

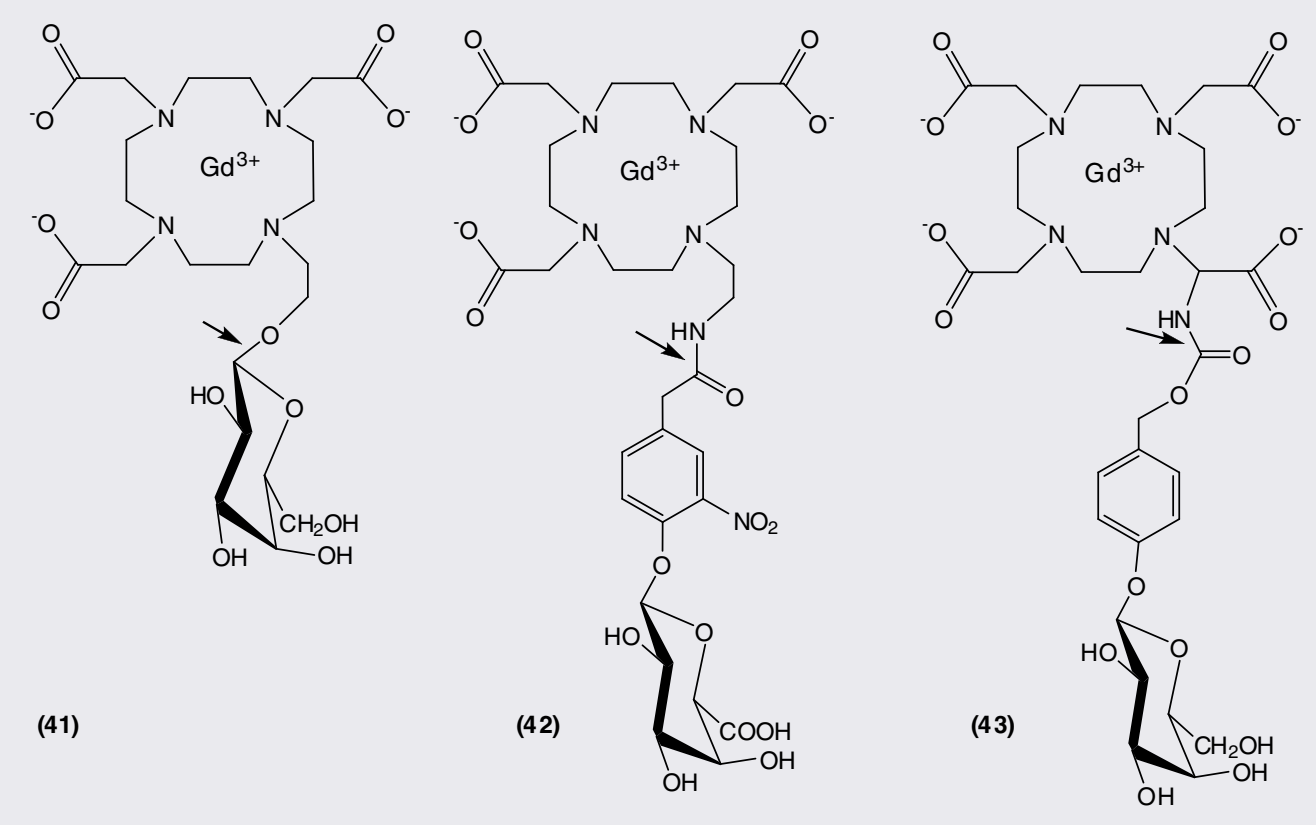

Figure 21. Enzyme-responsive contrast agents. The arrows indicate the places where enzymatic cleavage occurs. 
self-immolative linker, connecting a Yb-DOTA unit through an $\alpha$-carbamoyl nitrogen and $\beta$-Dgalactopyranoside 43 . As the result of the attack by $\beta$-galactosidase, the electron cascade is initiating the cleavage of carbamate, followed by transformation into an amine. The slowly exchanging magnetically nonequivalent amine protons were used to generate the PARACEST effect. This novel class of CAs has a great potential for detection of a variety of enzymes by a simple change of the glycosubstrate.

\section{Future perspective}

The rapid recent progress in glycobiology opens new avenues for the design of novel CAs based on molecular recognition of sugar moieties. The examples described in this review show that saccharides can be used both as targets and as targeting vectors. The structures of the compounds involved are relatively complicated and the synthesis of systems involving oligosaccharide moieties is particularly difficult. On the other hand, it may be expected that the developments in automated synthesis and in purification techniques will facilitate the development of efficient CAs for molecular imaging with the use of MRI. A general problem with molecular imaging is that the concentration of biomarkers of diseases usually is very low, particularly considering the intrinsic low sensitivity of MRI CAs. Therefore, amplification strategies to push up the sensitivity by introducing new MRI techniques, such as CEST, and delivering high payloads of paramagnetic metal ions at the sites of interests are of utmost importance [72]. It may be expected that nanoparticulate systems will play an important role in this respect [73]. Another important issue is that the magnetic-field strengths of the MRI equipment used for medical diagnosis are increasing. Most current MRI CAs have optimum performance at relatively low fields $(<1.5 \mathrm{~T}) . \mathrm{T}_{2}$ CAs show increasing relaxivity upon increasing magnetic field strength [74] and, therefore, this class of agents may gain further importance in the future.

The cost of commercialization of MRI CAs is huge, mainly due to the extremely high costs of the preclinical and clinical tests required. During the coming years, many new CAs will be developed in the laboratory, but only a few of the most promising ones will enter the stage of clinical tests. An important strategy to reduce the development costs is to build up the new molecular imaging CAs from a limited number of efficient reporting modules and a variety of targeting vectors, using efficient conjugation reactions, such as click reactions [75].

In vitro applications of responsive MRI CAs may have great potential in medical diagnosis, particularly in combination with high-throughput methods.

\footnotetext{
Financial \& competing interests disclosure

The authors thank the Fundação para a Ciência e a Tecnologia, Portugal (project PTDC/QUI/70063/2006) (MFF). This work was also carried out in the frame of the COST D38 Action and EU-FP6 'Network of Excellence' EMIL (grant no. LSHC-2004-503569) projects. The authors have no other relevant affiliations or financial involvement with any organization or entity with a financial interest in or financial conflict with the subject matter or materials discussed in the manuscript. This includes employment, consultancies, honoraria, stock ownership or options, expert testimony, grants or patents received or pending, or royalties.

No writing assistance was utilized in the production of this manuscript.
}

\section{Executive summary}

- In the field of molecular contrast agents new MRI contrast agents are emerging that are based on molecular recognition of carbohydrates. These agents have promising properties, which may be exploited in diagnostics for both in vivo and in vitro applications.

- Glycoconjugates play an important role in many biological processes and, consequently, these compounds are attractive targets for diagnostic agents. Important targets that are already identified in this field are the asialoglycoprotein receptor and the selectins, which can be targeted by ligands conjugated to galactosyl groups and Sialyl-Lewis $X$ mimics, respectively.

- Boronates are interesting artificial targeting vectors for sugars. Conjugates of lanthanide chelates and phenylboronic acid have been designed that can be applied for the molecular imaging of sialic acid, a sugar residue in glycoconjugates, which is overexpressed in tumors.

- Conjugates of lanthanide chelates and phenylboronic acid have also been successfully applied as responsive contrast agents for glycated human serum albumin and for glucose. This type of agents has found applications both in vitro and in vivo.

- MRI studies of perfused liver have shown that the combination of paramagnetic MRI contrast agents of this type and new MRI techniques, such as paramagnetic chemical exchange saturation transfer, have a great potential for the efficient mapping of the distribution of glucose in tissues. 


\section{Bibliography}

1 Weissleder R, Mahmood U. Molecular imaging. Radiology. 219, 316-333 (2001).

2 Davis AP, Wareham RS. Carbohydrate recognition through noncovalent interactions: a challenge for biomimetic and supramolecular chemistry. Angew. Chem. Int. Ed. 38, 2979-2996 (2001).

3 Seeberger PH. Chemical glycobiology: why now? Nat. Chem. Biol. 5, 368-372 (2009).

4 Plante OJ, Palmacci ER, Seeberger PH. Automated solid-phase synthesis of oligosaccharides. Science 291, 1523-1527 (2001).

5 Wilson RM, Danishefsky SJ. Fully synthetic carbohydrate-based antitumor vaccines. In: Cancer Vaccines and Tumor Immunity. Orentas R, Hodge JW, Johnson BD (Eds). John Wiley \& Sons, Inc., Hoboken, NJ, UK 15-27 (2008).

6 Wu CY, Liang PH, Wong CH. New development of glycan arrays. Org. Biomol. Chem. 7, 2247-2254 (2009).

7 Lis H, Sharon N. Lectins: carbohydratespecific proteins that mediate cellular recognition. Chem. Rev. 98, 637-674 (1998).

8 Rudd PM, Elliott T, Cresswell P, Wilson IA, Dwek RA. Glycosylation and the immune system. Science 291, 2370 - 2376 (2001).

9 Taylor ME, Drickamer K. Paradigms for glycan-binding receptors in cell adhesion. Curr. Opin. Cell Biol. 19, 572 -577 (2007).

10 Lundquist JJ, Toone EJ. The cluster glycoside effect. Chem. Rev. 102, 555-578 (2002).

11 Gabius H-J, André S, Kaltner H, Siebert H-C. The sugar code: functional lectinomics. Biochim. Biophys. Acta. 1572, 165-177 (2002).

12 Mammen M, Choi S-K, Whitesides GM. Polyvalent interactions in biological systems: implications for design and use of multivalent ligands and inhibitors. Angew. Chem. Int. Ed. 37, 2754- 2794 (1998).

13 Yamazaki N, Kojima S, Bovin NV, André S, Gabius S, Gabius H-J. Endogenous lectins as targets for drug delivery. Adv. Drug Delivery. Rev. 43, 225-244 (2000).

14 Coullerez G, Seeberger PH, Textor M. Merging organic and polymer chemistries to create glycomaterials for glycomics applications. Macromol. Biosci. 6, 634-647 (2006).

15 Weigel PH, Yik JHN. Glycans as endocytosis signals: the cases of the asialoglycoprotein and hyaluronan/chondroitin sulfate receptors. Biochim. Biophys. Acta Gen. Subj. 1572, 341-363 (2002).
16 Koyama Y, Ishikawa M, Yeda A, Sudo R, Kojima S, Sugunaka A. Body distribution of galactose-containing synthetic-polymer and galactosylated albumin. Polymer J. 25 , 355-361(1993).

17 Vera DR, Stadalnik R, Krohn K. Technetium99m galactosylneoglycoalbumin: preparation and preclinical studies. J. Nucl. Med. 10, 1157-1167 (1985).

18 Nakagima K, Kinuya K, Mizutani Y et al. Simple scintigraphic parameters with Tc-99m galactosyl human serum albumin for clinical staging of chronic hepatocellular disfunction. Ann. Nucl. Med. 13, 5-11 (1999).

19 Miki K, Kubota K, Inoue Y, Vera DR, Makuuchi M. Receptor measurements via Tc-GSA kinetic modeling are proportional to functional hepatocellular mass. J. Nucl. Med. 42, 733-737 (2001).

20 Colquhoum SD, Conelly CA, Vera DR. Portal-systemic shunts reduce asialoglycoprotein receptor density in rats. J. Nucl. Med. 42, 110-116 (2001).

21 Shuke N, Okizaki A, Kino S, Sato J et al. Functional mapping of regional liver asialoglycoprotein receptor amount from single blood sample and SPECT. J. Nucl. Med. 44, 475-482 (2003).

22 Sueyoshi K, Narabayashi I, Aratani T et al. Utility of Tc-99m GSA whole-body scintigraphy in detecting bone metastases from hepatocellular carcinoma. Clin. Nucl. Med. 26, 221-224 (2001).

23 Deal KA, Criste ME, Welsh MJ. Cellular distribution of ${ }^{111}$ In-DTPA galactose BSA in normal and asialoglycoprotein receptor deficient mouse liver. Nucl. Med. Biol. 25, 379-385 (1998).

24 Vera DR, Buonocore MH, Wisner ER, Katzberg RW, Stadalnik RC. A molecular receptor-binding contrast agent for magnetic resonance imaging of the liver. Acad. Radiol. 2, 497-506 (1995).

25 Gallez B, Lacour V, Demeure R et al. Spin labeled arabinogalactan as MRI contrast agent. Magn. Reson. Imag. 12, 61-69 (1994).

26 Schaffer BK, Linker C, Papisov M et al. Mion-ASF: biokinetics of an MR receptor agent. Magn. Reson. Imag. 11, 411-417 (1993).

27 Weissleder R, Reimer P, Lee AS, Wittenberg J, Brady TJ. MR receptor imaging: ultra small iron oxide particles targeted to asialoglycoprotein receptors. Am. J. Roentgenol. 155, 1161-1167 (1990).

28 Reimer P, Weissleder R, Lee AS, Buettner S, Wittenberg J, Brady TJ. Asialoglycoprotein receptor function in benign liver disease: evaluation with MR imaging. Radiology 178, 769-774 (1991).
29 Reimer P, Weissleder R,Wittenberg J, Brady TJ. Receptor-directed contrast agents for MR imaging: preclinical evaluation with afinity assays. Radiology 182, 565-569 (1992).

30 Reimer P, Kwong KK, Weisskoff R, Cohen MS, Brady TJ, Weissleder R. Dynamic signal intensity changes in liver with superparamagnetic MR contrast agents. J. Magn. Reson. Imag. 2, 177-181 (1992).

31 Gottschadt M, Schubert US. Prospects of metal complexes peripherally substituted with sugars in biomedicinal applications. Chem. Eur. J. 15, 1548-1557 (2009).

32 André JP, Geraldes CFGC, Martins JA et al. Lanthanide(III) complexes of DOTAglycoconjugates: a potential new class of lectin-mediated medical imaging agents. Chem. Eur. J. 10, 5804-5816 (2004).

33 Baía P, André JP, Geraldes CFGC, Martins JA, Merbach AE, Tóth É. Lanthanide(III) complexes of DTPA-bisamide glycoconjugates: potential imaging agents targeted for the asyaloglycoprotein receptor. Eur. J. Inorg. Chem. 2110-2119 (2005).

34 Torres S, Martins JA, André JP et al. Radiolabelled Sm-153 chelates of glycoconjugates: multivalence and topology effects on the targeting of the asialoglycoprotein receptor. Radiochim. Acta 95, 343-349 (2007).

35 Prata MIM, Santos AC, Torres S et al. Targeting of lanthanide(III) chelates of DOTA-type glycoconjugates to the hepatic asyaloglycoprotein receptor: cell internalization and animal imaging studies. Contrast Media Mol. Imaging 1, 246-258 (2006).

36 Fulton DA, Elemento EM, Aime S, Chaabane L, Botta M, Parker D. Glycoconjugates of gadolinium complexes for MRI applications. Chem. Commun. 1064-1066 (2006).

37 Alauddin MM, Louie AY, Shahinian A, Meade TJ, Conti PS. Receptor mediated uptake of a radiolabeled contrast agent sensitive to $\beta$-galactosidase activity. Nucl. Med. Biol.30, 261-265 (2003).

38 Kiefel MJ, von Itzstein M. Recent advances in the synthesis of sialic acid derivatives and sialylmimetics as biological probes. Chem. Rev. 102, 471-490 (2002).

39 Kogan TP, Dupre B, Keller KM et al. Rational design and synthesis of small molecule, non-oligosaccharide selectin inhibitors: ( $\alpha$-D-mannopyranosyloxy) biphenylsubstituted carboxylic acids. J. Med. Chem. 38, 4976-4984 (1995).

40 Fu YJ, Laurent S, Muller RN. Synthesis of a sialyl Lewis $(\mathrm{X})$ mimetic conjugated with DTPA, potential ligand of new contrast agents for medical imaging. Eur. J. Org. Chem. 3966-3973 (2002). 
41 Laurent S, Vander Elst L, Fu YJ, Muller RN. Synthesis and physicochemical characterization of Gd-DTPA-B $\left(s L e^{x}\right) A$, a new MRI contrast agent targeted to inflammation. Bioconjugate Chem. 15, 99-103 (2004).

42 Boutry S, Burtea C, Laurent S, Toubeau G, Vander Elst L, Muller RN. Magnetic resonance imaging of inflammation with a specific selectin-targeted contrast agent. Magn. Reson. Med. 53, 800-807 (2005).

43 Boutry S, Burtea C, Laurent S, Vander Elst L, Muller RN. Specific E-selectin targeting with a superparamagnetic MRI contrast agent. Contrast Media Mol. Imaging. 1, 15-22 (2006).

44 Rademacher KA, Beghein N, Boutry S et al. In vivo detection of inflammation using pegylated iron oxide particles targeted at E-selectin. A multimodal approach using MR imaging and EPR spectroscopy. Invest. Radiol. 44, 398-404 (2009).

45 Sibson NR, Blamire AM, Bernades-Silva M et al. MRI detection of early endothelial activation in brain inflammation. Magn. Reson. Med. 51, 248-252 (2004).

46 Barber PA, Foniok T, Kirk D et al. MR molecular imaging of early endothelial activation of focal ischemia. Ann. Neurol. 56, $116-120$ (2004).

47 Van Kasteren SI, Campbell SJ, Serres S, Anthony DC, Sibson NR, Davis BG. Glyconanoparticles allow pre-symptomatic in vivo imaging of brain disease. Proc. Natl Acad. Sci. USA 106, 18-23 (2009).

48 Chaubet F, Bertholon I, Serfaty JM, Bazeli R, Alsaid H, Jandrot-Perrus M. A new macromolecular paramagnetic MR contrast agent binds to activated human platelets. Contrast Media Mol. Imaging 2, 178-188 (2007).

49 Esposito, G, Crich SG, Aime S. Efficient cellular labeling by CD44 receptor-mediated uptake of cationic liposomes functionalized with hyaluronic acid and loaded with MRI contrast agents. ChemMedChem. 3, 1858-1862 (2008).

50 Schauer R. Achievements and challenges of sialic acid research. Glycoconjugate J. 17, 485-499 (2000).

51 Varki A, Kannagi R, Toole BP. Glycosylation changes in cancer. In: Essentials of Glycobiology (2nd Edition). Cold Spring Harbor Laboratory Press, NY, USA, 617-632 (2009).

52 Lemieux GA, Yarema KJ, Jacobs CL, Bertozzi CR. Exploiting differences in sialoside expression for selective targeting of MRI contrast reagents. J. Am. Chem. Soc. 121, 4278-4279 (1999).
53 Berg van der R, Peters JA, Bekkum van $\mathrm{H}$. The structure and (local) stability-constants of borate esters of mono- and di-saccharides as studied by ${ }^{11} \mathrm{~B}$ and ${ }^{13} \mathrm{C}$ NMR spectroscopy. Carbohydr. Res. 253, 1-12 (1994).

54 Djanashvili K, Frullano L, Peters JA. Molecular recognition of sialic acid end groups by phenylboronates. Chem. Eur. J. 11, 4010-4018 (2005).

55 Frullano L, Rohovec J, Aime S et al. Towards targeted MRI: new MRI contrast agents for sialic acid detection. Chem. Eur. J. 10, 5205-5217 (2004).

56 Djanashvili K, Koning GA, van der Meer AJGM, Wolterbeek HT, Peters JA.

Phenylboronate ${ }^{160} \mathrm{~Tb}$ complexes for molecular recognition of glycoproteins expressed on tumor cells. Contrast Media Mol. Imaging. 2, 35-41 (2007).

57 Cabella C, Geninatti Crich S, Corpillo D et al. Cellular labeling with Gd(III) chelates: only high thermodynamic stabilities prevent the cells acting as sponges of $\mathrm{Gd}^{3+}$ ions. Contrast Media Mol. Imaging 1, 23-29 (2006).

58 Armbruster DA. Fructoseamine: structure, analysis and clinical usefulness. Clin. Chem. 33, 2153-2163 (1987).

59 The Diabetes Control and Complications Trial Research Group. The effect of intensive treatment of diabetes on the development and progression of long-term complications in insulin-dependent diabetes mellitus. N. Engl. J. Med. 329, 1035-1036 (1993).

60 Rohovec J, Maschmeyer T, Aime S, Peters JA. The structure of the sugar residue in glycated human serum albumin and its molecular recognition by phenylboronate. Chem. Eur. J. 9, 2193-2199 (2003).

61 Aime S, Botta M, Dastru W, Fasano M, Panero M, Arnelli A. Synthesis and characterization of a novel DTPA-like gadolinium(III) complex: a potential reagent for the determination of glycated proteins by water proton NMR relaxation measurements. Inorg. Chem. 32, 2068-2071 (1993).

62 Battistini E, Mortillaro A, Aime S, Peters JA. Molecular recognition of sugars by lanthanide (III) complexes of a conjugate of $N, N$-bis[2-[bis[2-(1,1-dimethylethoxy)-2oxoethyl] amino] ethyl]glycine and phenylboronic acid. Contrast Media Mol. Imaging 2, 163-171 (2007).

63 Aime S, Digilio G, Fasano M, Paoletti S, Arnelli A, Ascenzi P. Metal complexes as allosteric effectors of human hemoglobin: an NMR study of the interaction of the gadolinium(III) bis(m-boroxyphenylamide) diethylenetriaminepentaacetic acid complex with human oxygenated and deoxygenated hemoglobin. Biophys. J. 76, 2735-2743 (1999).
64 Zhang S, Trokowski R, Sherry AD. A paramagnetic CEST agent for imaging glucose by MRI. J. Am. Chem. Soc. 125 , 15288-15289 (2003).

65 Trokowski R, Zhang S, Sherry AD. Cyclen-based phenylboronate ligands and their $\mathrm{Eu}^{3+}$ complexes for sensing glucose by MRI. Bioconjugate Chem. 15, 1431-1440 (2004).

66 Ren J, Trokowski R, Zhang S, Malloy CR, Sherry AD. Imaging the tissue distribution of glucose in livers using a PARACEST sensor. Magn. Reson. Med. 60, 1047-1055 (2008).

67 Ren J, Suh EH, Kovaks Z, Sherry AD. A new MRI PARACEST agent for sensing glucose. In: Proceedings of the 15th Annual Meeting of ISMRM. Berlin, Germany, 254 (2007).

68 Moats RA, Fraser SE, Meade TJ. A 'smart' magnetic resonance imaging agent that reports on specific enzymatic activity. Angew. Chem. Int. Ed. Eng. 36, 726-258 (1997).

69 Louie AY, Hüber MM, Ahrens ET et al. In vivo visualization of gene expression using magnetic resonance imaging. Nat. Biotechnol. 18, 321-325 (2000).

70 Duimstra JA, Femia FJ, Meade TJ. A gadolinium chelate for detection of $\beta$-glucoronidase: a self-immolative approach. J. Am. Chem. Soc. 127, 12847-12855 (2005).

71 Chauvin T, Durand P, Bernier M et al. Detection of enzymatic activity by PARACEST MRI : a general approach to target a large variety of enzymes. Angew. Chem. Int. Ed. 47, 4370-4372 (2008).

72 Aime S, Delli Castelli D, Geninatti Crich S, Gianolio E, Terreno E. Pushing the sensitivity envelope of lanthanide-based magnetic resonance imaging (MRI) contrast agents for molecular imaging applications. Acc. Chem. Res. 42, 822-831 (2009).

73 Marradi M, Alcántara D, de la Fuente JM, Garcia-Martín ML, Cerdán S, Penadés S. Paramagnetic Gd-based gold glyconanoparticles as probes for MRI: tuning relaxivities with sugars. Chem. Commun. 3922-3924 (2009).

74 Gossuin Y, Gillis P, Hocq A, Vuong QL, Roch A. Megnetic resonance relaxation properties of superparamagnetic particles. Wiley Interdisciplinary Reviews: Nanomedicine and Nanobiotechnology. 1, 299-310 (2009).

75 Mullen DG, Desai AM, Waddell JN et al. The implications of stochastic synthesis for the conjugation of functional groups to nanoparticles. Bioconjugate Chem. 19, 1748-1752 (2008). 